The Phillips curve under state-dependent pricing

Hasan Bakhshi, Hashmat Khan and Barbara Rudolf

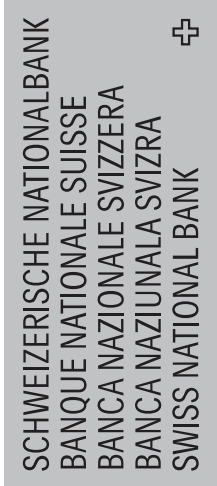

$\frac{n}{0}$

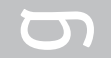

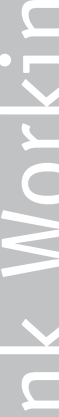

ro

a

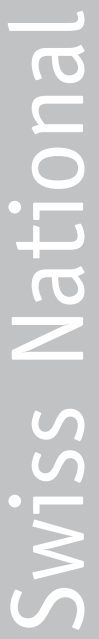


The views expressed in this paper are those of the author(s) and do not necessarily represent those of the Swiss National Bank. Working Papers describe research in progress. Their aim is to elicit comments and to further debate.

ISSN $1660-7716$

๑ 2005 by Swiss National Bank, Börsenstrasse 15, P.0. Box, CH-8022 Zurich 


\title{
The Phillips curve under state-dependent pricing
}

\author{
Hasan Bakhshi* Hashmat Khan ${ }^{\dagger}$ Barbara Rudolf ${ }^{\ddagger}$ \\ Bank of England Bank of England Swiss National Bank
}

\section{January 2005}

\begin{abstract}
This paper is related to a large recent literature studying the Phillips curve in sticky-price equilibrium models. It differs in allowing for the degree of price stickiness to be determined endogenously. A closed-form solution for short-term inflation is derived from the dynamic stochastic general equilibrium (DSGE) model with state-dependent pricing originally developed by Dotsey, King and Wolman. This generalised Phillips curve encompasses the New Keynesian Phillips curve (NKPC) based on Calvo-type price-setting as a special case. It describes current inflation as a function of lagged inflation, expected future inflation, and current and expected future real marginal costs. The paper demonstrates that inflation dynamics generated by the model for a broad class of time and state-dependent price-setting behaviours are well approximated by the popular hybrid NKPC (with one lag of inflation) in a low-inflation environment. This provides an explanation of why the hybrid NKPC performs well in describing inflation dynamics across industrial countries. It implies, however, that the reduced-form coefficients of the hybrid NKPC may not have a structural interpretation.
\end{abstract}

Keywords: State-dependent pricing, inflation dynamics, Phillips curve.

JEL Classification: E31, E32

The views in this paper are our own and should not be interpreted as those of the Bank of England or the Swiss National Bank. We would like to thank Pablo Burriel-Llombart, Michael Dotsey, Mikhail Golosov, Robert King, Richard Mash, Alexander Wolman, Mathias Zurlinden, and seminar participants at the European University Institute and the Bank of Finland for helpful discussions and comments. We also thank Alexander Wolman for providing us with the code from Dotsey, King and Wolman (1999).

\footnotetext{
*hasan.bakhshi@bankofengland.co.uk

†hashmat.khan@bankofengland.co.uk

$\ddagger$ Corresponding author: barbara.rudolf@snb.ch
} 


\section{Introduction}

The Phillips curve has long served as a useful description of monetary policy effects on inflation. In modern New Keynesian models, it is explicitly derived from the pricing decisions of firms. One advantage of this new approach is that because the relationship has a structural interpretation, we can, for example, infer implications for the transmission of inflation following a shock; the Phillips curve is no longer a 'black box'. But if there are structural changes in the economy, such as the move to a low-inflation environment witnessed since the 1990s in the United Kingdom and several other countries, the price-setting behaviour of firms may change and affect inflation dynamics. From a policy perspective, therefore, two important issues arise. First, how sensitive is short-term inflation dynamics to such shifts in the economic environment? Second, how well does a Phillips curve based on the assumption of unchanged price-setting behaviour of firms describe inflation dynamics of an economy where the former has in fact changed?

In recent years, dynamic general equilibrium models with nominal rigidities have become the standard tool to analyse the effects of monetary policy on output and prices. These models regularly assume some form of staggered price-setting with an exogenous timing of price changes (time-dependent pricing). The implication is that firms do not adjust the time pattern of their price adjustments in response to changes in macroeconomic conditions. This is hardly plausible if we think of an environment with shifts in trend inflation, for example, and may limit the value of these models for monetary policy analysis. In response to this problem, Dotsey et al. (1999) have developed a dynamic general equilibrium model with endogenous timing of price changes. Building on earlier contributions by Sheshinski and Weiss (1983) and Caplin and Leahy (1991), they describe an economy where the firms' time pattern of price changes responds to the state of the economy (state-dependent pricing). Recent contributions to the literature have developed state-dependent pricing models that emphasise the role of sticky pricing plans (Burstein (2002)) and idiosyncratic marginal cost shocks (Golosov and Lucas (2003)).

The analysis of monetary policy in dynamic general equilibrium models is usually performed by numerical methods. Nevertheless, it is useful for many purposes to have a closed-form solution for short-term inflation. In the case of time-dependent pricing, a structural equation relating 
inflation dynamics to the level of real marginal costs (or another measure of real activity) has been derived from the Calvo (1983) model. Under zero trend inflation, it relates inflation to marginal costs and the expectation of next period's inflation. This is the New Keynesian Phillips curve (NKPC). ${ }^{1}$

In this paper, we derive a closed-form solution for short-term inflation from the Dotsey et al. (1999) model. The resulting equation is less compact than the New Keynesian Phillips curve. It relates inflation to lagged inflation, expected future inflation, and current and expected future real marginal costs. The number of leads and the size of the coefficients are endogenous and depend on the level of steady-state inflation and on firms' beliefs about future adjustment costs. We refer to this structural equation as the state-dependent Phillips curve (SDPC).

In contrast to the NKPC, the SDPC allows lagged inflation terms to affect current inflation. This is an interesting feature since estimates presented by Galí and Gertler (1999) and Galí et al. (2003) among others suggest that the NKPC extended by a lagged inflation term provides a better description of inflation dynamics than the purely forward-looking NKPC. There are various ways to derive a specification with lagged inflation beyond the SDPC. Three approaches have been considered in the recent literature. First, Galí and Gertler (1999) extend the Calvo (1983) model to allow for a subset of sellers that resort to a backward-looking rule of thumb to set prices. Second, Christiano et al. (2001) assume backward-looking indexation of wages and prices to the aggregate price level. Third, Wolman (1999), Dotsey (2002), Guerrieri (2002), Kozicki and Tinsley (2002), and Mash (2003) use other forms of time-dependent models of price-setting that build on the staggered contract model of Taylor (1980). While all three approaches provide lagged inflation terms, the structure of these Phillips curves is conditional on the assumption about exogenous nominal rigidities. So a key advantage of the SDPC over this class of Phillips curves is its endogenous structure. This aspect can offer guidance to policymakers on how structural changes can affect inflation dynamics.

Given the empirical evidence suggesting that the NKPC with a lagged inflation term performs well for several countries, the question arises whether the data generating process underlying the SDPC is realistic. To explore this issue, we generate artificial data based on various calibrations

\footnotetext{
${ }^{1}$ See Woodford (2003) for a detailed exposition.
} 
of the state-dependent model and estimate the NKPC with one lagged inflation term, ie the hybrid Phillips curve of Galí and Gertler (1999), using the GMM approach. Our findings suggest that the parsimonious structure of the hybrid NKPC is a good reduced-form description of inflation dynamics for a wide range of time and state-dependent price-setting behaviour in a low-inflation environment. However, the reduced-form coefficients of the hybrid NKPC may not have a structural interpretation. In this sense, the hybrid NKPC may still share the weaknesses of the traditional Phillips curve approach.

The paper is organised as follows. Section 2 reviews the main features of the state-dependent model by Dotsey et al. (1999). Section 3 derives the SDPC and shows that this generalised Phillips curve nests the NKPC. To explore the SDPC, Section 4 shows how it varies with the price-setting characteristics at the firm level (price adjustment cost assumption) and trend inflation. Section 5 confronts the SDPC with the hybrid NKPC. We generate artificial data sets from the state-dependent model for a range of calibrations and discuss the performance of the hybrid NKPC in describing the dynamics of these data sets. Section 6 concludes.

\section{The state-dependent pricing model}

The framework we use in this paper is the dynamic stochastic general equilibrium model with state-dependent pricing of Dotsey et al. (1999). The economy studied by these authors is characterised by monopolistic competition between firms selling final goods. With a common technology and common factor markets real marginal costs are the same for all firms. The novel feature of the model is the way price adjustment costs are introduced. It is assumed that firms face stochastic costs of price adjustment which are i.i.d. across firms and across time. Firms evaluating their prices weigh the expected benefit from price adjustment against the price adjustment cost they have drawn in the current period. Conditional on the current adjustment costs, some firms do adjust while others do not. All adjusting firms set the same price.

In this section, we focus on the key equations describing the optimal nominal price and the aggregate price level, respectively. The rest of the model is familiar and formal details can be found in Dotsey et al. (1999). To simplify the presentation, we split the price-setting problem 
into two parts. For a given realisation of the adjustment cost, each firm has to decide whether to adjust the price of the final good it produces and, if so, to what level. The former can be characterised by the dynamic programming problem

$$
V_{t}=\max \left(v_{0, t}-\xi_{t} w_{t}, v_{j, t}\right)
$$

where $v_{0, t}$ gives the current value of the firm if it adjusts the price in the current period, and $v_{j, t}$ is the firm's value if it keeps the price set $j$ periods ago unchanged. The price adjustment cost is denoted by $\xi_{t} w_{t}$, where $\xi_{t}$ is the realisation of the stochastic adjustment cost expressed in labour units, and $w_{t}$ is the real price of labour.

The value of the firm in case of a price adjustment in $t$ is determined by

$$
v_{0, t}=\max _{P_{0, t}}\left\{z_{0, t}+E_{t} \beta Q_{t, t+1}\left[\left(1-\alpha_{1, t+1}\right) v_{1, t+1}+\alpha_{1, t+1}\left(v_{0, t+1}-w_{t+1} \alpha_{1, t+1}^{-1} \Xi_{1, t+1}\right)\right]\right\}
$$

with

$$
\Xi_{1, t+1}=\int_{0}^{G^{-1}\left(\alpha_{1, t+1}\right)} \xi g(x) d x
$$

The corresponding value of the firm in case of no price adjustment in $t$ is

$$
v_{j, t}=z_{j, t}+E_{t} \beta Q_{t, t+1}\left[\left(1-\alpha_{j+1, t+1}\right) v_{j+1, t+1}+\alpha_{j+1, t+1}\left(v_{0, t+1}-w_{t+1} \alpha_{j+1, t+1}^{-1} \Xi_{j+1, t+1}\right)\right]
$$

with

$$
\Xi_{j+1, t+1}=\int_{0}^{G^{-1}\left(\alpha_{j+1, t+1}\right)} \xi g(x) d x
$$

where $z_{j, t}$ denotes the current real profit based on the optimal price set $j$ periods ago, $P_{j, t}$, and the term in the square brackets reflects the two possibilities of adjustment and non-adjustment next period. With probability $1-\alpha_{j+1, t+1}$, the firm will not adjust its price next period; in this case, we have the discounted expected value of a non-adjusting firm, $E_{t}\left[\beta Q_{t, t+1} v_{j+1, t+1}\right]$, where $\beta Q_{t, t+1}$ is the discount factor which varies with the ratio of future to current marginal utility. With probability $\alpha_{j+1, t+1}$, the firm will adjust its price next period; in this case, we have the discounted expected value of an adjusting firm, $E_{t}\left[\beta Q_{t, t+1} v_{0, t+1}\right]$, less the expected adjustment cost the firm will have to pay, amounting to $E_{t}\left[w_{t+1} \alpha_{j+1, t+1}^{-1} \Xi_{j+1, t+1}\right]$. The average cost in labour units paid conditional on adjustment, $\alpha_{j+1, t+1}^{-1} \Xi_{j+1, t+1}$, depends on $G^{-1}\left(\alpha_{j+1, t+1}\right)$, where $G(\cdot)$ denotes the distribution of the fixed price adjustment cost. Equation (2.2) refers to a firm which 
does adjust its price in the current period, so that $j=0$; otherwise the interpretation is the same as in (2.3).

Now a firm will change its price only if the benefit of a price adjustment exceeds the realisation of the random adjustment cost. Formally,

$$
v_{0, t}-v_{j, t} \geq w_{t} \xi_{t}, \quad \forall j=1,2, \ldots, J
$$

If both sides of (2.4) are equal, the firm is indifferent between adjusting its price and keeping it unchanged. This borderline case can be used to derive the price adjustment probability $\alpha_{j, t}$ of a firm that adjusted its price $j$ periods ago. It is the likelihood of drawing an adjustment cost that is smaller than the benefit expressed in labour units, $\left(v_{0, t}-v_{j, t}\right) / w_{t}$. This can be written as

$$
\alpha_{j, t}=G\left(\frac{v_{0, t}-v_{j, t}}{w_{t}}\right), \quad \forall j=1,2 \ldots, J
$$

Equation (2.5) describes how the adjustment probabilities depend on the state of the economy. As the value functions evolve stochastically with the state of the economy, the adjustment probabilities $\alpha_{j, t} \forall j=1,2, \ldots, J$, also change. Note that $J$ is the maximum number of periods the firm is willing to do without a price adjustment. It is finite because, with adjustment costs bounded from above and positive trend inflation, the net benefit of a price adjustment becomes arbitrarily large over time. The state-dependent behaviour of the adjustment probabilities is a key feature of the model. It captures the intuitive notion that adjustment behaviour responds to shocks, and that with positive inflation a firm which last changed its price a long time ago is more likely to readjust than a firm which changed its price more recently.

The adjustment probabilities $\alpha_{j, t}, \forall j=1,2, \ldots, J$, can then be used to describe the distribution of price vintages in the economy and the evolution of this distribution through time. Let the firms at the beginning of period $t$ be ordered according to the time that has elapsed since their most recent price adjustment $\tau_{j, t}, \forall j=1,2, \ldots, J$, where $\sum_{i=1}^{J} \tau_{j, t}=1$. In period $t$, a fraction $\alpha_{j, t}$ of vintage- $j$ firms decides to adjust in accordance with (2.4), and a fraction $\left(1-\alpha_{j, t}\right)$ decides to stick to the old price $P_{j, t}$. The total fraction of firms adjusting in period $t$, $\omega_{0, t}$, is therefore

$$
\omega_{0, t}=\sum_{j=1}^{J} \alpha_{j, t} \tau_{j, t}
$$


and the fractions of the other firms, ie the firms that last adjusted their prices $j$ periods ago, are

$$
\omega_{j, t}=\left(1-\alpha_{j t}\right) \tau_{j, t}, \quad \forall j=1,2, \ldots, J-1
$$

The end-of-period fractions then define the distribution of the price vintages at the beginning of period $t+1: \tau_{j+1, t+1}=\omega_{j, t}, \forall j=0,1, \ldots, J-1$. Note that the fraction of adjusting firms, $\omega_{0, t}$, is conditional on the exogenous adjustment cost distribution function $G(\xi)$. In Section 4.1 below, we will examine the sensitivity of the optimal price-setting behaviour with respect to different assumptions for $G(\cdot)$.

We then turn to the second aspect of the firm's price-setting problem, that is the determination of the optimal nominal price $P_{0, t}$. The adjusting firm will choose $P_{0, t}$ such that $v_{0, t}$ is maximised. Differentiating (2.2) with respect to $P_{0, t}$ and removing $v_{1, t+1}$ by recursive forward substitution leads to the optimality condition

$$
0=E_{t} \sum_{j=0}^{J-1} \beta^{j} Q_{t, t+j} \frac{\omega_{j, t+j}}{\omega_{0, t}} \frac{\partial z_{j, t+j}}{\partial P_{0, t}}
$$

with

$$
\begin{gathered}
\omega_{j, t+j} / \omega_{0, t}=\prod_{i=1}^{j}\left(1-\alpha_{i, t+i}\right) \\
\frac{\partial z_{j, t+j}}{\partial P_{0, t}}=\frac{1-\theta}{P_{t+j}}\left[\frac{P_{0, t}}{P_{t+j}}\right]^{-\theta} C_{t+j}+\frac{\theta}{P_{t+j}}\left[\frac{P_{0, t}}{P_{t+j}}\right]^{-\theta-1} M C_{t+j} C_{t+j}
\end{gathered}
$$

where $M C_{t+j}, C_{t+j}$, and $P_{t+j}$ denote aggregate real marginal costs, aggregate demand and aggregate prices, and $\theta$ is the elasticity of substitution between goods (or equally, the elasticity of demand for any single good). Equation (2.8) is the dynamic counterpart to the static optimality condition for the monopolistic firm's price-setting problem. It requires the sum of the discounted marginal profits due to a price adjustment to be zero, or, since the profits are defined as revenues minus costs, the sum of discounted expected marginal revenues to equal the sum of expected marginal costs. With common factor markets, the firm's real marginal costs in turn can be expressed as a function of aggregate real marginal costs and aggregate prices.

Solving (2.8) for the optimal price $P_{0, t}$, yields

$$
P_{0, t}=\frac{\theta}{\theta-1} \frac{E_{t} \sum_{j=0}^{J-1} \beta^{j} Q_{t, t+j} \frac{\omega_{j, t+j}}{\omega_{0, t}} M C_{t+j} P_{t+j}^{\theta} C_{t+j}}{E_{t} \sum_{j=0}^{J-1} \beta^{j} Q_{t, t+j} \frac{\omega_{j, t+j}}{\omega_{0, t}} P_{t+j}^{\theta-1} C_{t+j}}
$$


This is the central pricing equation and corresponds to that in Dotsey et al. (1999). The optimal price depends on current and expected future aggregate real marginal costs, aggregate demand and aggregate prices. The weights, $E_{t} \omega_{j, t+j} / \omega_{0, t}$, reflect the expected probabilities to be stuck with the currently set price for $j$ periods, $E_{t} \prod_{i=1}^{j}\left(1-\alpha_{i, t+i}\right)$. These conditional probabilities are endogenous and vary in response to changes in the state variables. They would be neither endogenous nor time varying in a purely time-dependent model.

As all firms have identical marginal costs and identical expectations of future adjustment costs, $P_{0, t}$ is the same for all adjusting firms. ${ }^{2}$ Therefore, the aggregate price level $P_{t}$ can be written as a convex combination of $P_{0, t-j}$, the nominal prices set by the firms of the $J$ price vintages:

$$
P_{t} \equiv\left[\sum_{j=0}^{J-1} \omega_{j, t}\left(P_{0, t-j}\right)^{1-\theta}\right]^{\frac{1}{1-\theta}}
$$

A revision of the price adjustment probabilities induced by a shock to the money supply, for example, thus affects the persistence of the aggregate price level through the reweighting of individual prices in (2.10).

\section{The state-dependent Phillips curve (SDPC)}

\subsection{Derivation}

This section discusses the derivation of a Phillips curve from the model outlined in Section 2 . The key equations are (2.9) describing the optimal nominal price set by adjusting firms, $P_{0, t}$, and (2.10) describing the aggregate price level, $P_{t}$. Starting from (2.9), we can divide both sides of the equation by $P_{t}$ to get relative prices. By log-linearising around the steady state and solving for the optimal relative price $x_{0, t}$, one obtains

\footnotetext{
${ }^{2}$ Golosov and Lucas (2003) present a menu-cost model in which firms set prices optimally in response to both aggregate and idiosyncratic shocks. In this set-up price adjusting firms may charge different prices.
} 


$$
x_{0, t}=E_{t} \sum_{j=1}^{J-1} \sum_{i=j}^{J-1}\left[\theta \rho_{i}+(1-\theta) \delta_{i}\right] \pi_{t+j}+E_{t} \sum_{j=0}^{J-1}\left\{\psi_{j} m c_{t+j}+\left(\rho_{j}-\delta_{j}\right)\left[\hat{\omega}_{j, t+j}-\hat{\omega}_{0, t}\right]\right\}
$$

with

$$
\rho_{j}=\frac{\beta^{j} \omega_{j} \Pi^{j \theta}}{\sum_{i=0}^{J-1} \beta^{i} \omega_{i} \Pi^{i \theta}} \quad \delta_{j}=\frac{\beta^{j} \omega_{j} \Pi^{j(\theta-1)}}{\sum_{i=0}^{J-1} \beta^{i} \omega_{i} \Pi^{i(\theta-1)}} \quad \psi_{j}=\rho_{j}+\kappa\left(\rho_{j}-\delta_{j}\right)
$$

where the $\hat{\omega}$-terms denote absolute deviations and the other time-varying lower-case letters denote percentage deviations from their respective steady-state values. Appendix A summarises the main steps of this derivation. Equation (3.1) describes the variations of the optimal relative price around its steady state, $x_{0, t}$, as a function of the expected deviations of future inflation, $\pi_{t+j}$, of current and future real marginal costs, $m c_{t+j}$, and of future probabilities of non-adjustment, $\hat{\omega}_{j, t+j}-\hat{\omega}_{0, t}$, from their steady-state values. The coefficients depend on steady-state inflation, $\Pi$, the steady-state distribution of price vintages, $\omega_{j}$, the number of price vintages, $J$, the real discount factor, $\beta$, the price elasticity of demand, $\theta$, and the elasticity of aggregate demand with respect to real marginal costs, $\kappa$. With an increase in steady-state inflation for instance, the benefit of adjusting relative prices is rising for all firms. Hence, the adjustment probabilities are increasing (according to (2.4)), and the structure and number of the $\omega_{j}$-terms are moving (according to (2.6) and (2.7)), thereby affecting the magnitude of the coefficients in (3.1) endogenously.

Starting from (2.10), we then derive the log-linearised version of the aggregate price level in terms of $x_{0, t}$. In Appendix A we show that this yields

$$
\begin{gathered}
x_{0, t}=\mu_{0} \pi_{t}+\sum_{j=1}^{J-2} \mu_{j} \pi_{t-j}-\sum_{j=1}^{J-1} \omega_{j} \nu_{j} x_{0, t-j}+\frac{1}{1-\theta} \sum_{j=0}^{J-1} \nu_{j} \hat{\omega}_{j, t} \\
\mu_{j}=\frac{1}{\omega_{0}} \sum_{i=j+1}^{J-1} \omega_{i} \Pi^{i(\theta-1)} \quad \nu_{j}=\frac{1}{\omega_{0}} \Pi^{j(\theta-1)}
\end{gathered}
$$

We define $\hat{\Omega}_{t}=\sum_{j=0}^{J-1} \nu_{j} \hat{\omega}_{j, t}$. Thus, we have that

$$
x_{0, t}=\mu_{0} \pi_{t}+\sum_{j=1}^{J-2} \mu_{j} \pi_{t-j}-\sum_{j=1}^{J-1} \omega_{j} \nu_{j} x_{0, t-j}+\frac{1}{1-\theta} \hat{\Omega}_{t}
$$


Equation (3.3) indicates that $x_{0, t}$ is related to deviations of current and lagged inflation, $\pi_{t-j}$, and of lagged optimal relative prices, $x_{0, t-j}$, from their steady-state values. Further it is related to the deviation of the distribution of price vintages from the steady state, $\hat{\Omega}_{t}$. The coefficients, in turn, depend on steady-state inflation, $\Pi$, the steady-state distribution of price vintages, $\omega_{j}$, the number of price vintages, $J$, and the price elasticity of demand, $\theta$. As in (3.1), the parameter structure in (3.2) moves state-dependently. That is, with an increase in steady-state inflation, the steady-state adjustment probabilities and thus the distribution of price vintages change endogenously. Since the aggregate price level depends on the distribution of price vintages, the shifting pattern of the distribution caused by the increase in steady-state inflation affects the dynamics of the aggregate price level expressed in terms of $x_{0, t}$.

To obtain an equation for the dynamics of inflation, we combine (3.1) and (3.3) and solve for $\pi_{t}$ :

$$
\begin{array}{r}
\pi_{t}=\frac{1}{\mu_{0}}\left[\sum_{j=1}^{J-1} \sum_{i=j}^{J-1}\left[\theta \rho_{i}+(1-\theta) \delta_{i}\right] \pi_{t+j}+E_{t} \sum_{j=0}^{J-1} \psi_{j} m c_{t+j}+E_{t} \sum_{j=0}^{J-1}\left(\rho_{j}-\delta_{j}\right)\left[\hat{\omega}_{j, t+j}-\hat{\omega}_{0, t}\right]\right. \\
\left.-\sum_{j=1}^{J-2} \mu_{j} \pi_{t-j}+\sum_{j=1}^{J-1} \omega_{j} \nu_{j} x_{0, t-j}-\frac{1}{1-\theta} \hat{\Omega}_{t}\right]
\end{array}
$$

Applying iterative backward substitution to (3.3) allows us to eliminate all optimal relative price terms in (3.4). The procedure is outlined in Appendix B. The equation for the inflation dynamics then becomes

$$
\pi_{t}=E_{t} \sum_{j=1}^{J-1} \delta_{j}^{\prime} \pi_{t+j}+E_{t} \sum_{j=0}^{J-1} \psi_{j}^{\prime} m c_{t+j}+E_{t} \sum_{j=0}^{J-1} \gamma_{j}\left[\hat{\omega}_{j, t+j}-\hat{\omega}_{0, t}\right]+\sum_{j=1}^{\infty} \mu_{j}^{\prime} \pi_{t-j}+\sum_{j=0}^{\infty} \varrho_{j} \hat{\Omega}_{t-j}
$$

where

$$
\begin{gathered}
\delta_{j}^{\prime}=\frac{1}{\mu_{0}} \sum_{i=j}^{J-1}\left[\theta \rho_{i}+(1-\theta) \delta_{i}\right] \quad \psi_{j}^{\prime}=\frac{1}{\mu_{0}} \psi_{j} \quad \gamma_{j}=\frac{1}{\mu_{0}}\left(\rho_{j}-\delta_{j}\right) \\
\mu_{j}^{\prime}=\frac{1}{\mu_{0}}\left(\sum_{i=1}^{j} \vec{e}\left[H(-B)^{i-1} A\right]_{[., j-(i-1)]}-\mu_{j}\right), \quad \mu_{j}=0, \forall j \geq J-1 \\
\varrho_{0}=-\frac{1}{\mu_{0}} \frac{1}{1-\theta} \quad \varrho_{j}=\frac{1}{\mu_{0}} \sum_{i=1}^{j} \vec{e}\left[H(-B)^{i-1} C\right]_{[., j-(i-1)]} \quad \forall j \geq 1
\end{gathered}
$$


The details about the matrices $H, A, B$ and $C$ are given in Appendix B. It is sufficient to note here that $\vec{e}$ is a unity row vector with $[(j+1)(J-1)-1]$ elements and that the matrices $H$, $A, B$ and $C$ are square matrices of order $[(j+1)(J-1)-1]$. The subscript $[., j-(i-1)]$ then denotes the column of matrix $\left[H(-B)^{(i-1)} A\right]$ and $\left[H(-B)^{(i-1)}\right]$ which are premultiplied by $\vec{e}$.

We refer to (3.5) as the state-dependent Phillips curve (SDPC). According to the SDPC, the deviation of current inflation from the steady state, $\pi_{t}$, depends on the deviations from their respective steady-state values of lagged inflation, $\pi_{t-j}$, expected future inflation, $\pi_{t+j}$, current and expected future real marginal costs, $m c_{t+j}$, expected future probabilities of non-adjustment, $\hat{\omega}_{j, t+j}-\hat{\omega}_{0, t}$, and of the lagged distributions of price vintages, $\hat{\Omega}_{t-j}$.

The number of leads for $\pi_{t+j}, m c_{t+j}$, and $\hat{\omega}_{j, t+j}-\hat{\omega}_{0, t}$ are finite, while the number of lags for $\pi_{t-j}$ and $\hat{\Omega}_{t-j}$ are infinite. The infinite lag structure results from the elimination of the relative prices. However, the coefficients on these lags can be shown to converge to zero since the price adjustment cost and therefore the price-setting behaviour is stochastic implying that $\omega_{0, t}>\omega_{j, t}$, $\forall j=1,2, \ldots, J-1$. How fast this comes about depends again on the assumption made about the adjustment cost distribution and on the state of the economy.

The coefficients in the SDPC depend on steady-state inflation, the steady-state distribution of price vintages, the number of price vintages, and the price elasticity of demand. Those on the expected variables also depend on the real discount factor; those on the marginal cost terms, further depend on the elasticity of aggregate demand with respect to real marginal costs. The price adjustment costs are not made explicit in (3.5), but they are lingering in the background. By affecting the number and the distribution of price vintages, they are indirectly linked to the coefficients of the SDPC. Thus we conclude that with a change in the distribution of adjustment costs or a change in steady-state inflation, the structure of the SDPC will change as well. We have suggested already how an increase in steady-state inflation influences the optimal pricing behaviour in the state-dependent model. In Section 4, we shall give a more detailed account based on numerical methods and figures. 


\subsection{Nesting the New Keynesian Phillips curve}

A substantial amount of recent research in monetary economics has focused on theoretical and empirical issues related to the NKPC. The NKPC states that current inflation depends on next period's expected inflation and on marginal costs or another measure of economic activity:

$$
\pi_{t}=\beta E_{t} \pi_{t+1}+\frac{\alpha(1-\beta(1-\alpha))}{(1-\alpha)} m c_{t}
$$

This specification can be derived from a dynamic equilibrium model with monopolistic competition and Calvo-type price stickiness. ${ }^{3}$ Calvo (1983) assumes that the price-setter adjusts his or her price whenever a random signal occurs. The signals are i.i.d. across firms and across time. Thus, there is a constant probability $\alpha$ that a given price-setter will be able to reset his or her price in a given period. The adjustment probability is independent of the time that has elapsed since the previous price adjustment, and the adjustment frequency does not depend on the state of the economy.

If we consider the Dotsey et al. (1999) model under the assumption that price-setting follows Calvo (1983) and that the level of steady-state inflation is constant at zero (ie, $\Pi=1$ in gross terms), we can show that the SDPC representation of inflation dynamics collapses to the NKPC. Since the Calvo pricing assumption implies that the adjustment probability is constant for all firms, $\alpha_{j, t}=\alpha$, the number of price vintages becomes infinite and the weights of the price vintages can be written as a function of $\alpha$ and $j$ :

$$
\omega_{j, t}=\alpha(1-\alpha)^{j}, \quad \forall j=0,1, \ldots \infty
$$

With these modifications, (3.5) takes the form

$$
\pi_{t}=E_{t} \sum_{j=1}^{\infty} \delta_{j}^{\prime} \pi_{t+j}+E_{t} \sum_{j=0}^{\infty} \psi_{j}^{\prime} m c_{t+j}+E_{t} \sum_{j=0}^{\infty} \gamma_{j}\left[\hat{\omega}_{j, t+j}-\hat{\omega}_{0, t}\right]+\sum_{j=1}^{\infty} \mu_{j}^{\prime} \pi_{t-j}+\sum_{j=0}^{\infty} \varrho_{j} \hat{\Omega}_{t-j}
$$

where

$$
\delta_{j}^{\prime}=\frac{\alpha}{(1-\alpha)} \beta^{j}(1-\alpha)^{j} \quad \psi_{j}^{\prime}=\frac{\alpha(1-\beta(1-\alpha))}{(1-\alpha)} \beta^{j}(1-\alpha)^{j} \quad \gamma_{j}=0 \quad \mu_{j}^{\prime}=0 \quad \varrho_{j}=0
$$

\footnotetext{
${ }^{3}$ For the derivation of the NKPC see Galí and Gertler (1999) or Sbordone (2002).
} 
There are three points to note here. First, under the assumption of Calvo-type price-setting and zero trend inflation, the SDPC does not include any lagged terms. This is the consequence of the definition of the aggregate price level in (2.10). The infinite geometric lag structure allows us to abstract from the weights of the previously set optimal prices and to summarise the whole pricing history in terms of the previous period's aggregate price level. This result holds regardless the level of steady-state inflation. Second, the effect of the state-dependent pricing behaviour (reflected in (3.5) by $\hat{\omega}_{j, t+j}-\hat{\omega}_{0, t}, \hat{\Omega}_{t-j}$ ) disappears. Third, equation (3.7) includes an infinite number of leads for expected inflation and expected real marginal costs. As shown in Figure 1, the coefficients on these leaded variables take a geometrically falling and infinite form. ${ }^{4}$

After isolating expected next period's inflation and current marginal costs in (3.7), the SDPC representation of the Calvo model takes the form

$$
\begin{aligned}
\pi_{t}=\alpha \beta E_{t} \pi_{t+1} & +\frac{\alpha(1-\beta(1-\alpha))}{(1-\alpha)} m c_{t} \\
& +\frac{\alpha}{(1-\alpha)} \sum_{j=2}^{\infty} \beta^{j}(1-\alpha)^{j} E_{t} \pi_{t+j}+\frac{\alpha(1-\beta(1-\alpha))}{(1-\alpha)} \sum_{j=1}^{\infty} \beta^{j}(1-\alpha)^{j} E_{t} m c_{t+j}
\end{aligned}
$$

The geometrically falling and infinite coefficient structure then allows us to express the whole lead structure in (3.8) in terms of $E_{t} \pi_{t+1}$ :

$$
\beta(1-\alpha) E_{t} \pi_{t+1}=\frac{\alpha}{(1-\alpha)} \sum_{j=2}^{\infty} \beta^{j}(1-\alpha)^{j} E_{t} \pi_{t+j}+\frac{\alpha(1-\beta(1-\alpha))}{(1-\alpha)} \sum_{j=1}^{\infty} \beta^{j}(1-\alpha)^{j} E_{t} m c_{t+j}
$$

Making use of (3.9), the SDPC representation in equation (3.8) reduces to the NKPC in (3.6). ${ }^{5}$ The quantitative effect of this simplification on the coefficient of $E_{t} \pi_{t+1}$ is exhibited in Figure 1. The coefficient on expected next period's inflation is $\alpha \beta$ in the SDPC representation of the Calvo model and $\beta$ in the NKPC. Since $0<\alpha<1$, the coefficient is larger in the NKPC. Note that the coefficient on current real marginal costs is the same in both representations.

\footnotetext{
${ }^{4}$ Although the actual number of leads is infinite in the Calvo model, there are only 15 leads displayed in Chart 1.

${ }^{5}$ Similarly, it can be shown that the SDPC nests the NKPC specifications derived under positive trend inflation by Ascari (2004) and Bakhshi et al. (2003).
} 


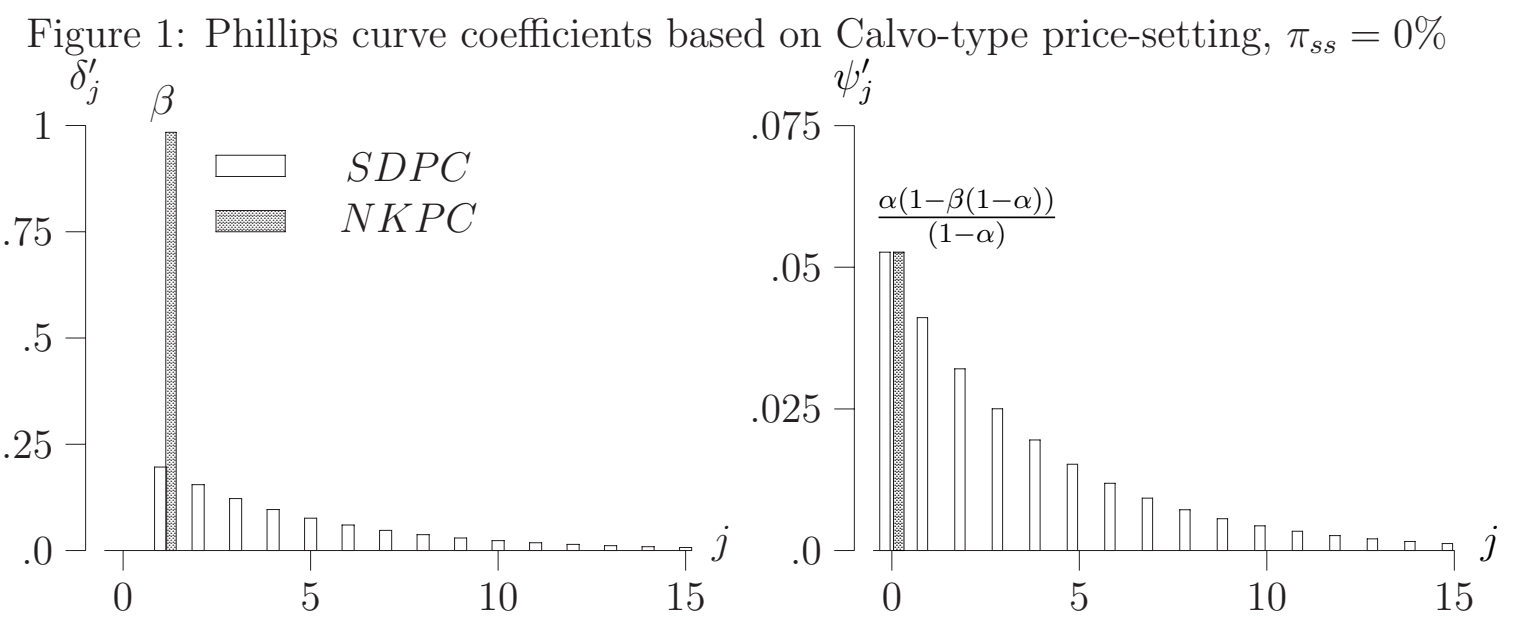

\section{Evaluation of the SDPC}

We now evaluate the SDPC with respect to different rates of steady-state inflation and different types of price-setting. One way of describing price-setting behaviour is by the sequence of adjustment probabilities $\left[\alpha_{1}, \ldots, \alpha_{j}, \ldots, \alpha_{J-1}\right]^{\prime}$ considered by the firm. We compare three such sequences which are based on three different distributions of price adjustment costs.

Figure 2: Cumulative distribution functions (C.D.F.) of fixed adjustment costs

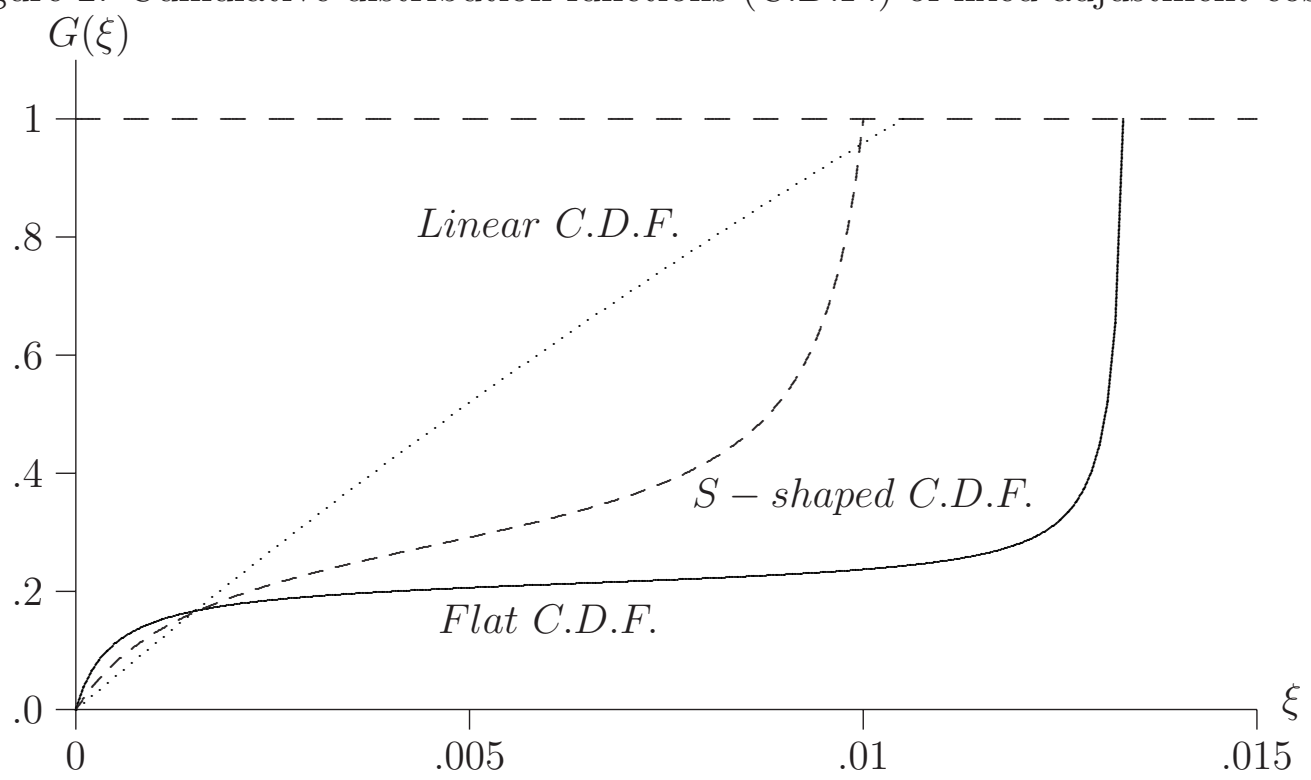

Following Dotsey et al. (1999), the three distribution functions are assumed to have the 
form $G(\xi)=c_{1}+c_{2} \tan \left[c_{3} \xi-c_{4}\right]$. The calibrations are chosen such that the average duration of price rigidity turns out to be six quarters for a steady-state inflation rate of $3 \% .{ }^{6}$ The rest of the model calibration is the same for all three cases of price-setting. As suggested by Dotsey et al. (1999), we take $\beta=0.984$ for the quarterly real discount rate, $\Pi=1.03$ (in gross terms) for the annual steady-state inflation rate, and $\theta=4.33$ for the price elasticity of demand. The alternative steady-state inflation rate we use for comparison is $\Pi=1.06$ (in gross terms).

Table 1 summarises the calibrations and Figure 2 illustrates the three distributions of price adjustment costs. The first, labelled 'flat C.D.F.', indicates that a firm is likely to draw either a very small or a very large adjustment cost over the interval [0,0.0133]. The likelihood of drawing an intermediate adjustment cost is very small. The second distribution function, labelled 'Sshaped C.D.F.', implies that a firm still is likely to draw either a small or a large adjustment cost; but the interval now is $[0,0.010]$ and the likelihood of drawing an adjustment cost in the middle range is higher than under the first distribution function. ${ }^{7}$ The third function, labelled 'linear C.D.F.', approximates a uniform distribution of adjustment costs over the interval [0, 0.0105].

\subsection{Steady-state comparisons of adjustment probabilities and fractions of firms in price vintages}

We start our evaluation by looking at the steady-state adjustment probabilities, $\alpha_{j}$, and the corresponding distribution of price vintages, $\omega_{j}$. Figure 3 summarises the results for the three types of price-setting behaviour and the two levels of steady-state inflation. The horizontal axis indicates the vintages ordered by the number of quarters $j$ since the price has been set.

We notice that the adjustment probability $\alpha_{j}$ is rising in $j$ in all three models. This is due to the fact that in an inflationary environment the benefit of adjusting prices is larger for firms of vintage $j+1$ than for firms of vintage $j$, resulting in a higher adjustment probability. Take the model with the S-shaped C.D.F. as an example. If $\pi_{s s}=3 \%$, firms which adjusted their price

\footnotetext{
${ }^{6}$ This benchmark calibration is slightly higher than the durations of price rigidity reported in the literature. See Wolman (2000) for a survey.

${ }^{7}$ The S-shaped distribution function is qualitatively similar to that adopted by Dotsey et al. (1999). Recently, Klenow and Kryvtsov (2003) have calibrated the parameters of the distribution function to monthly micro data underlying the US CPI for the period 1988-2003. Their calibration implies a distribution function which is similar in shape to the one underlying the Calvo model.
} 
Table 1: Model calibrations

\begin{tabular}{|c|c|c|c|}
\hline & PARAMETERS & SymbOL & VALUES \\
\hline \multirow[t]{3}{*}{ Preferences } & Quarterly discount factor & $\beta$ & 0.984 \\
\hline & Risk aversion & $\sigma$ & 0 \\
\hline & Labour supply elasticity & & $\infty$ \\
\hline \multirow[t]{2}{*}{ Technology } & Labour share & $\alpha_{L}$ & 0.667 \\
\hline & Demand elasticity & $\theta$ & 4.33 \\
\hline \multirow[t]{15}{*}{ Adjustment costs } & Flat C.D.F. & $c_{1}$ & 0.2142 \\
\hline & & $c_{2}$ & 0.02273 \\
\hline & & $c_{3}$ & 226.088 \\
\hline & & $c_{4}$ & 1.4651 \\
\hline & & $B$ & 0.0133 \\
\hline & S-shaped C.D.F. & $c_{1}$ & 0.2793 \\
\hline & & $c_{2}$ & 0.1111 \\
\hline & & $c_{3}$ & 260.9951 \\
\hline & & $c_{4}$ & 1.1921 \\
\hline & & $B$ & 0.01 \\
\hline & Linear C.D.F. & $c_{1}$ & 4.7124 \\
\hline & & $c_{2}$ & 2.5 \\
\hline & & $c_{3}$ & 9.9907 \\
\hline & & $c_{4}$ & 1.0830 \\
\hline & & $B$ & 0.0105 \\
\hline Steady-state inflation & & $\pi_{s s}$ & $3 \%$ and $6 \%$ \\
\hline
\end{tabular}

Notes: $B=$ upper bound of price adjustment costs. 
Figure 3: Characterisation of steady-state price-setting behaviour Flat C.D.F.
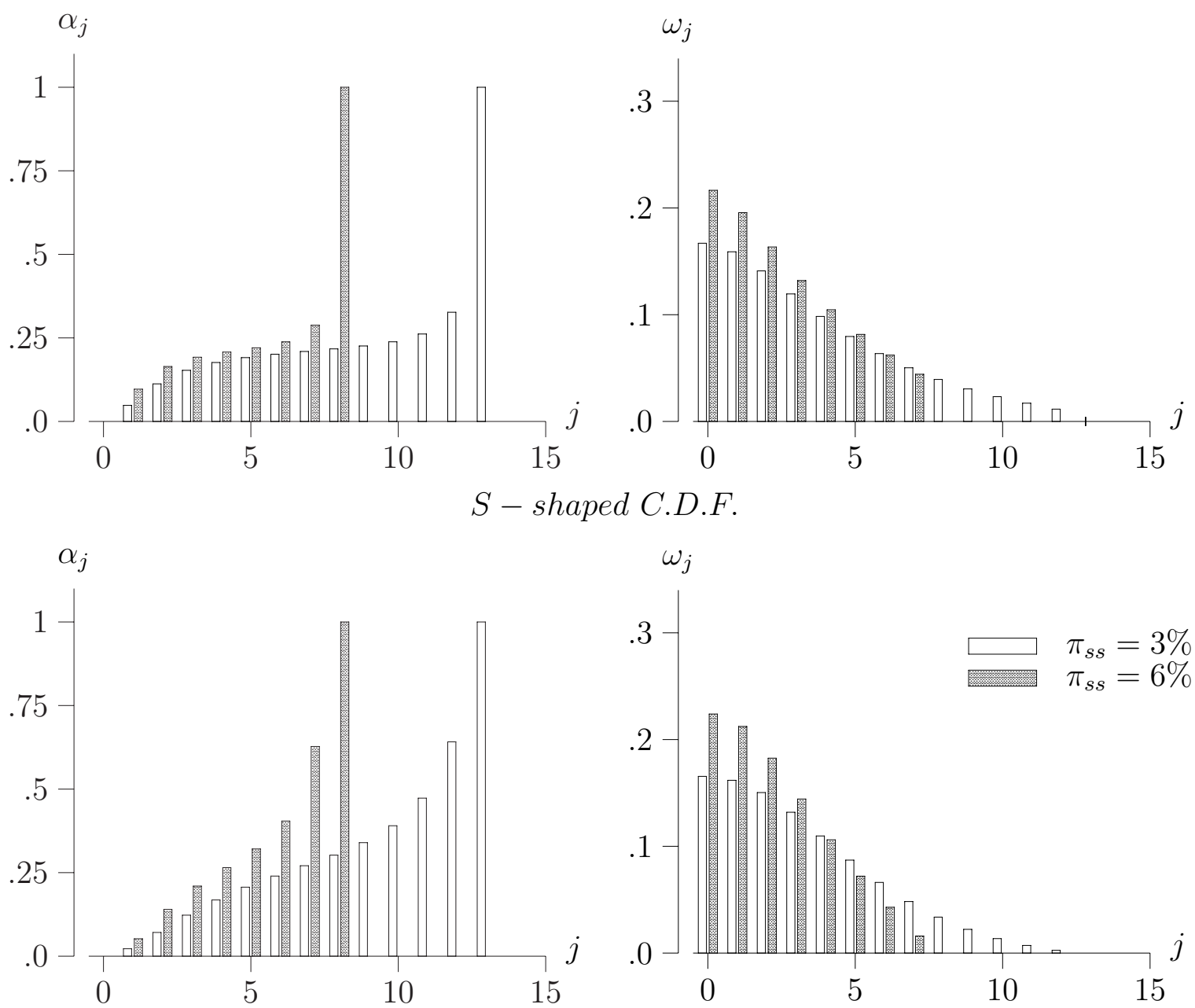

Linear C.D.F.
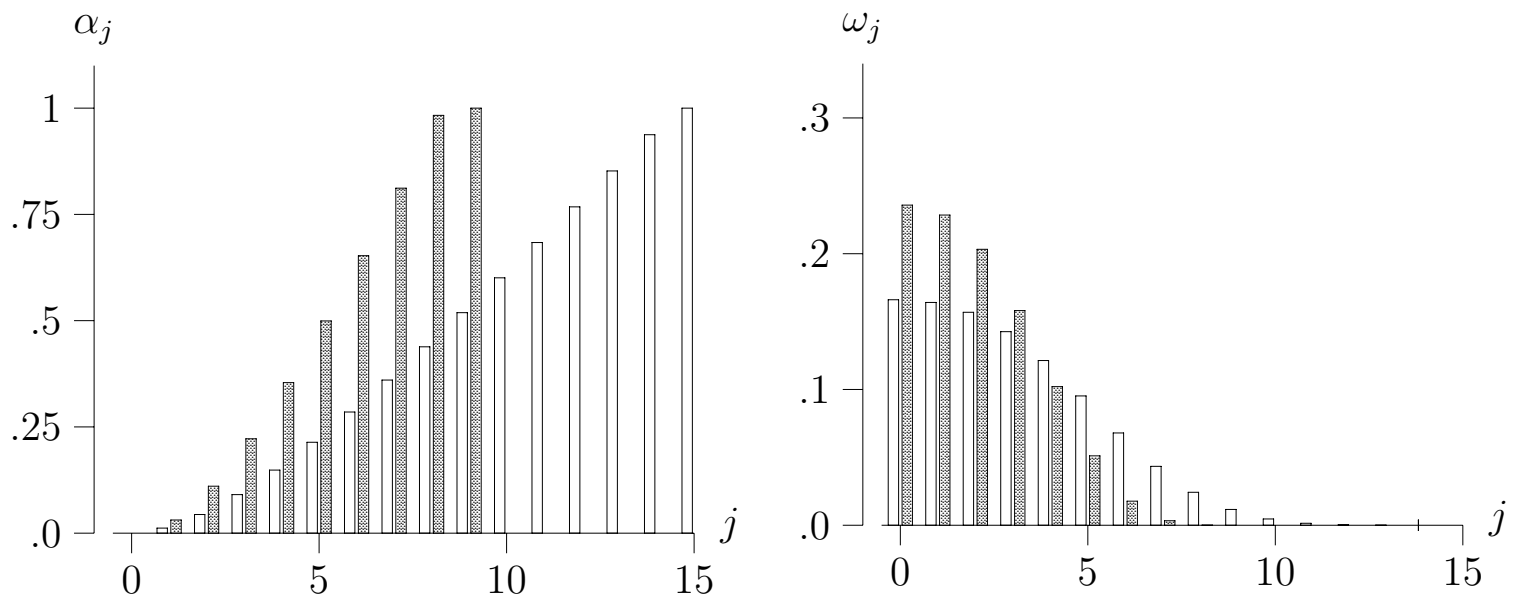
in the previous period $(j=1)$ adjust again in the current period with a probability of $2 \%$. This reflects the relatively small benefit of readjusting after just one period. In contrast, firms which set their price ten periods ago $(j=10)$ expect a sizable profit gain from readjusting; hence the probability of adjusting in the current period exceeds $40 \%$.

Moreover, notice that the adjustment probability $\alpha_{j}$ increases with the level of steady-state inflation. Since the relative prices of the firms erode more rapidly under high inflation, the firms adjust their prices more frequently. Also, the increase in the rate of steady-state inflation lowers the number of price vintages. Consider the model with the S-shaped C.D.F. There are 13 price vintages when steady-state inflation is $3 \%$. As the steady-state inflation rises to $6 \%$, the number of vintages declines to 8 . Simultaneously, the average duration of price rigidity falls from 6 quarters to 4.5 quarters.

Turning to the fractions of firms in the different price vintages, we note that the fractions are declining with rising $j$. Also, with higher steady-state inflation, the number of price vintages is smaller and the number of firms in the vintages with low $j$ is larger. In our example, $\omega_{0}$ increases from 0.17 at $3 \%$ inflation to 0.22 at $6 \%$ inflation.

Finally, we observe that the shape of the adjustment probabilities differs depending on the adjustment cost distribution function. This difference is not transmitted to the distribution of price vintages, however. At least for low rates of steady-state inflation, the distribution of relative prices is strikingly similar across the three price-setting assumptions.

\subsection{Different types of price-setting behaviour and the SDPC}

We have seen that differences between adjustment cost distributions cause substantial differences between sequences of adjustment probabilities. Here we ask how those different distributions translate into different implications for the coefficients in the SDPC.

Figure 4 displays the SDPC coefficients computed for the various adjustment cost distribution functions (flat C.D.F., S-shaped C.D.F. and linear C.D.F.) under the assumption of 3\% steady-state inflation. The leads $(+)$ and lags $(-)$ of the variables are given on the horizontal 
axis, the size of the coefficients on the vertical axis. We can see that the coefficients on expected future inflation, $\delta_{j}^{\prime}$, and on current and expected future real marginal costs, $\psi_{j}^{\prime}$, take their highest values at low leads and fall off smoothly with higher leads in a slightly convex pattern. Figure 4 displays only 10 leads, although the maximum lead $J-1$ is 12 or 14 , depending on the adjustment cost distribution. Note that the pattern of the coefficients is not too different from the one we observed in the SDPC representation of the Calvo model (see Figure 1). The coefficients on lagged inflation, $\mu_{j}^{\prime}$, are quantitatively important at low lags but fall off rapidly at higher lags and converge to zero in an oscillating pattern. The coefficients which are related to the state-dependent nature of price-setting, $\varrho_{j}$ and $\gamma_{j}$, are all negligible in size, with $\varrho_{0}$ as the only exception.

Turning to the different types of price-setting behaviour, the main result is that the SDPC coefficients are remarkably similar across the three adjustment cost distribution functions. The differences between the three functions (all calibrated such that the average duration of price rigidity is six quarters) have little effect on the reduced-form coefficients of the SDPC. To understand this result, we consult the definitions of the coefficients. According to (3.5) the coefficients depend on the level of steady-state inflation rate, $\Pi$, the number of different price vintages in the economy, $J$, the steady-state fractions of different price vintages, $\omega_{j}$, the steadystate real discount factor, $\beta$, the price elasticity of demand, $\theta$, and the elasticity of aggregate demand with respect to marginal costs, $\kappa$. We know from our assumptions that $\Pi=3 \%$, $\beta=0.984, \theta=4.33$ and $\kappa$ are the same in all three models. Also, we have noticed in the preceding section that the number of price vintages (flat C.D.F.: $J=13$, S-shaped C.D.F.: $J=13$, linear C.D.F.: $J=15)$ and the distribution of price vintages, $\omega_{j}$, vary little across the three models despite marked differences in the sequences of adjustment probabilities. Thus, the similarity can be traced back to the parameters and steady-state values going into the reducedform coefficients of the SDPC, which are all either equal or similar across the three types of price-setting behaviour. 
Figure 4: Coefficients in the SDPC for different types of price-setting behaviour, $\pi_{s s}=3 \%$ Inflation coefficients $\delta_{j}^{\prime}$ and $\mu_{j}^{\prime}$
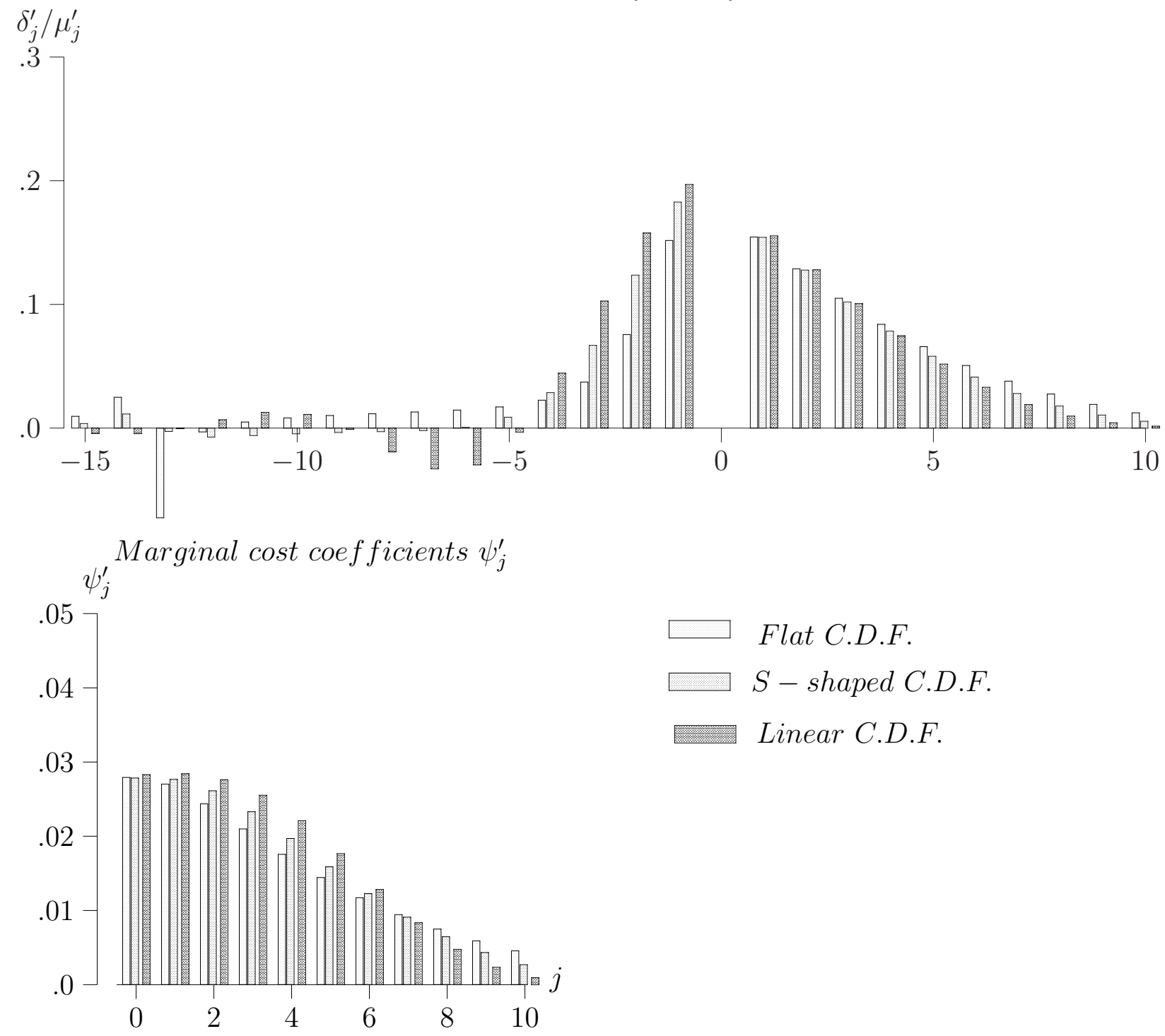

$\square$ Flat C.D.F.

$\square S-$ shaped C.D.F.

Linear C.D.F.

State - dependent behaviour coefficients $\varrho_{j}$ and $\gamma_{j}$
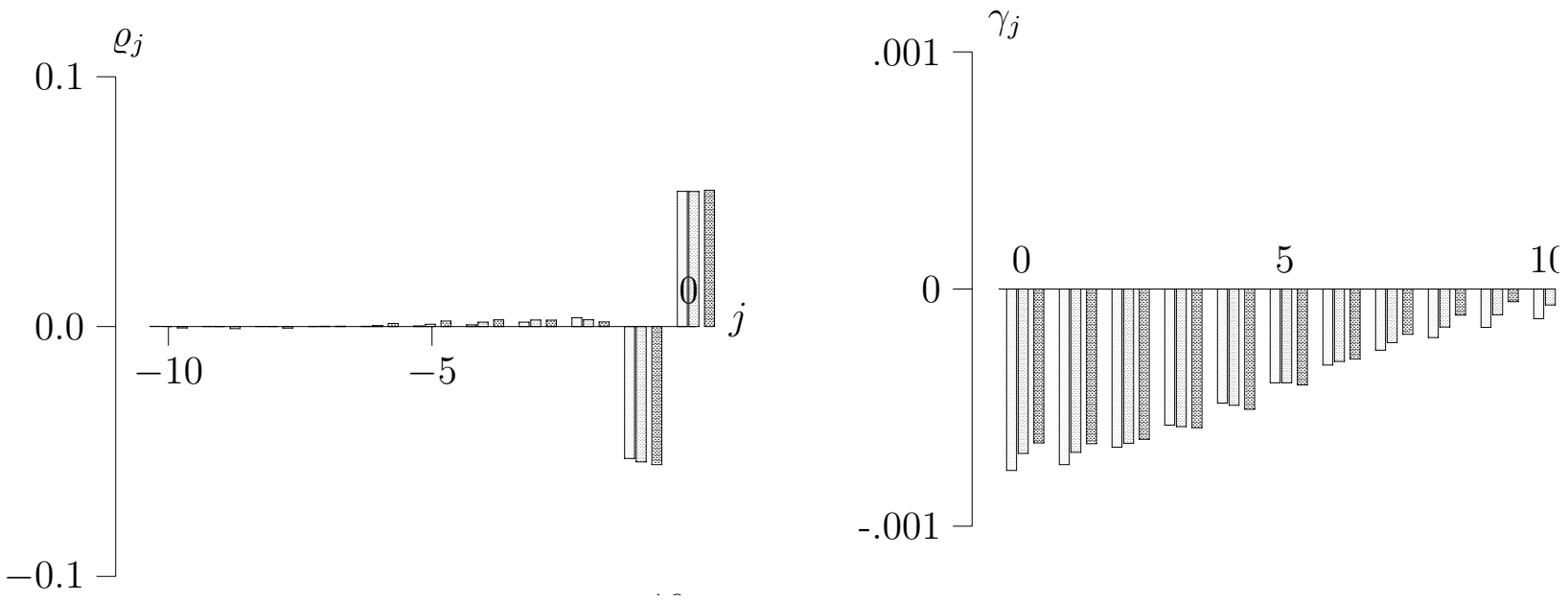
Figure 5: Reduced-form coefficients in the SDPC when steady-state inflation moves Inflation coefficients $\delta_{j}^{\prime}$ and $\mu_{j}^{\prime}$
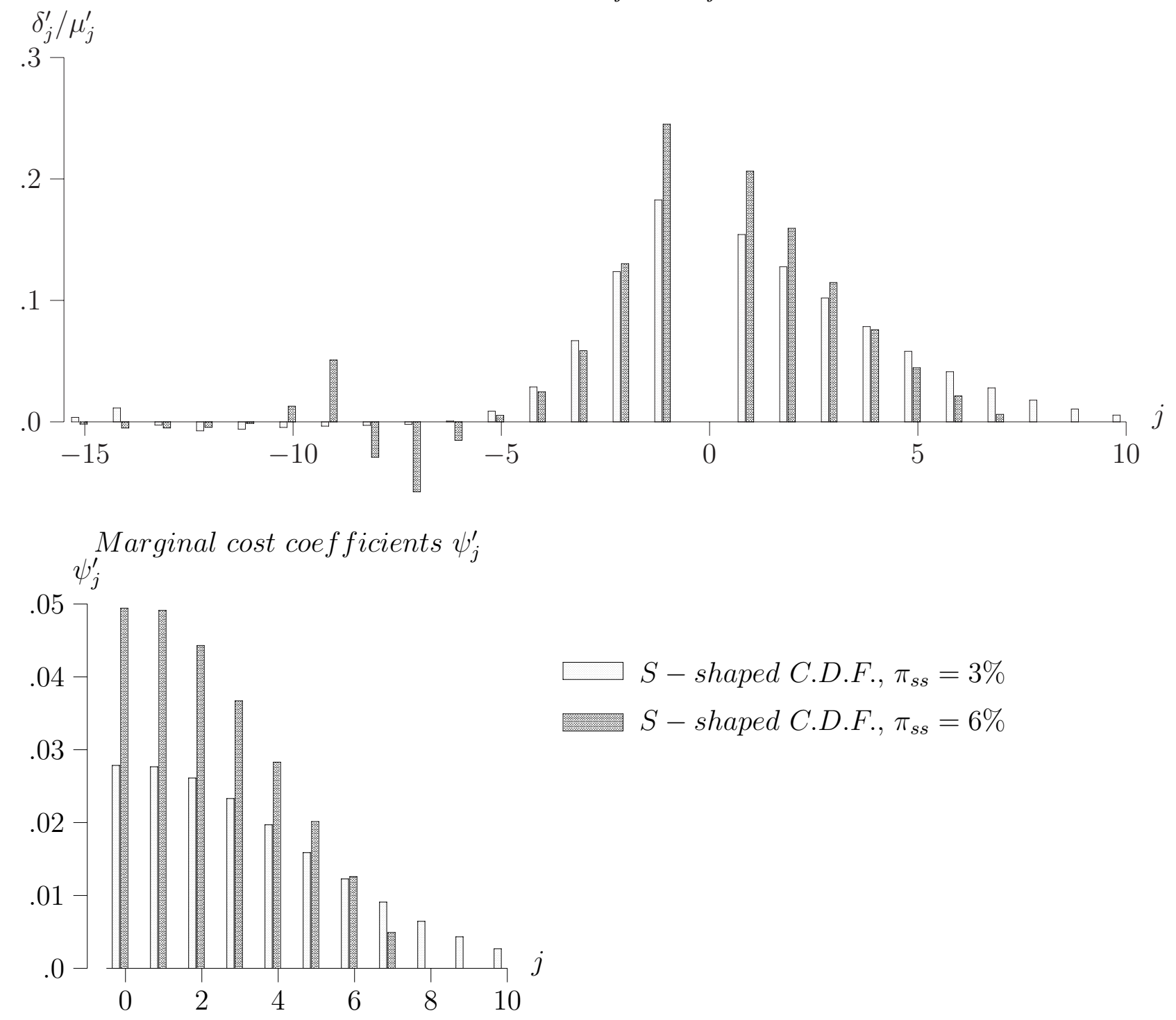

State - dependent behaviour coefficients $\varrho_{j}$ and $\gamma_{j}$
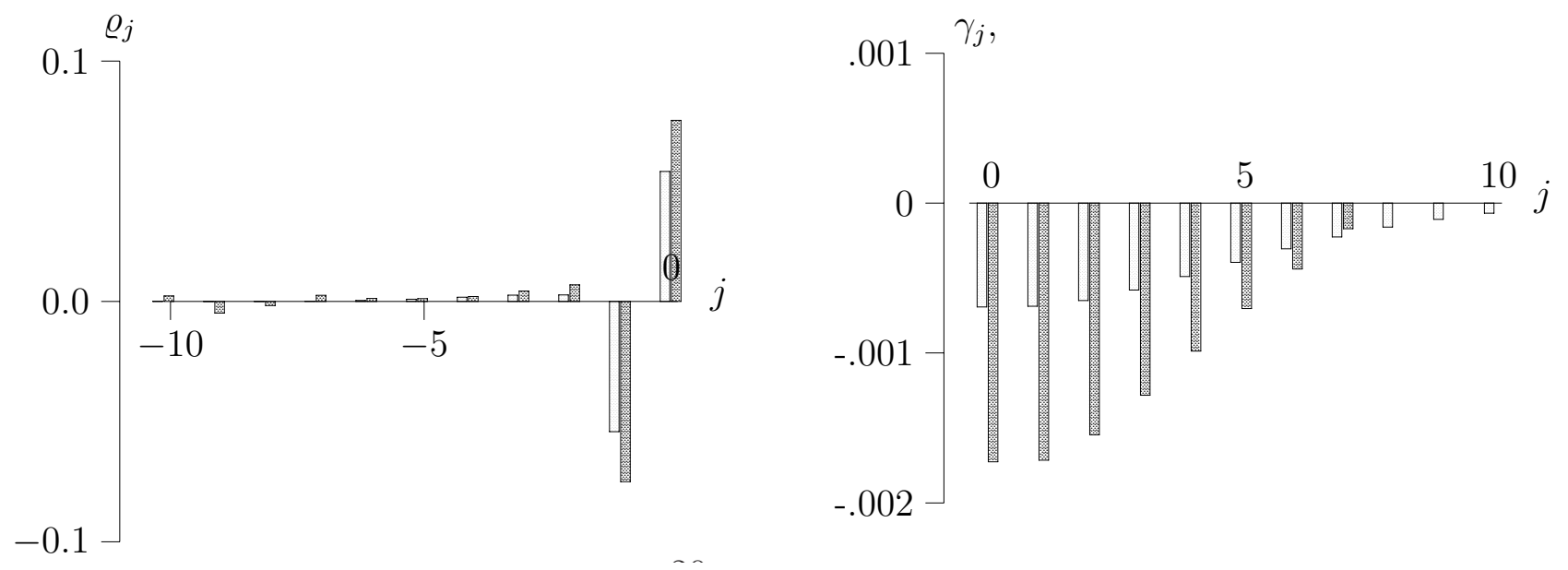


\subsection{Different steady-state inflation rates and the SDPC}

Finally, we explore the effect of the steady-state inflation rate on the reduced-form coefficients of the SDPC. The two steady-state inflation rates considered are $3 \%$ and $6 \%$. The adjustment cost distribution function assumed throughout is the S-shaped C.D.F..

We have seen in Figure 3 that a higher level of steady-state inflation leads to an upward revision of the optimal adjustment probabilities. As a consequence, prices are adjusted more frequently. The number of price vintages, $J$, declines and the distribution of price vintages, $\omega_{j}$, is modified. The other factors determining the reduced-form coefficients of the $\operatorname{SDPC}(\beta, \theta$ and $\kappa)$ are not affected by the increase in steady-state inflation.

As shown in the top panel of Figure 5, the number of leads falls to 7 (from 12) when steadystate inflation is raised to $6 \%$. The coefficients on expected future inflation, $\delta_{j}^{\prime}$, on current and future marginal costs, $\psi_{j}^{\prime}$, and on the expected variations in state-dependent price-setting behaviour, $\gamma_{j}$, increase with inflation at low leads while falling off more rapidly at higher leads. Also, the size of the coefficients increases on low lags of inflation, but falls off more rapidly with increasing lag length. At the same time, the oscillating pattern gets more distinct. Note, finally, that the coefficients on expectations about future state-dependent deviations from steady-state adjustment behaviour are still negligible.

\section{An interpretation of the hybrid NKPC}

In this section, we examine whether the hybrid NKPC is a good empirical approximation to the inflation dynamics generated by a plausibly calibrated model with state-dependent pricing. The hybrid NKPC was proposed by Galí and Gertler (1999). They assume that some firms set their prices in a forward-looking optimising way based on Calvo (1983), while the other firms apply a backward-looking rule of thumb. The resulting equation is

$$
\pi_{t}=\gamma_{b} \pi_{t-1}+\gamma_{f} E_{t} \pi_{t+1}+\lambda m c_{t}
$$


Similar specifications have been derived by Christiano et al. (2001) adding full dynamic indexation, and by Woodford (2003) adding partial dynamic indexation to Calvo-type pricesetting. ${ }^{8}$ Empirical evidence suggests that the hybrid NKPC does well empirically and provides a better description of inflation dynamics than the purely forward-looking NKPC. Examples are Galí and Gertler (1999), Galí et al. (2001), Gagnon and Khan (2004), Leith and Malley (2002), Smets and Wouters (2003), and Sbordone (2003). ${ }^{9}$ Galí et al. (2003) present evidence for the robustness of the hybrid NKPC in response to criticisms by Rudd and Whelan (2002) and Linde $(2003) \cdot{ }^{10}$

To examine the hybrid NKPC in the context of a model with state-dependent pricing, we start by doing stochastic simulations of the full Dotsey et al. (1999) model to generate artificial data sets. There are three types of shocks: money supply shocks, money demand shocks and technology shocks. All shocks are assumed to follow an AR(1) process with a persistence parameter of 0.5 ; otherwise, the three shocks are mutually independent. The standard deviation of the innovation to a shock is $1 \%$. We generate 1,000 samples of 150 quarterly observations for each case considered. Overall, we consider twelve different cases based on three different calibrations of the distribution of price adjustment costs (flat C.D.F., S-shaped C.D.F., and linear C.D.F.), two levels of steady-state inflation (3\% and 6\%), and both time-dependent and state-dependent simulations of the model. In the state-dependent simulations (SD), the adjustment probabilities vary over time in response to a shock, while in the time-dependent simulations (TD), the adjustment probabilities are restricted to stay constant at their steady-state solutions implying that $\hat{\omega}_{j, t+j}-\hat{\omega}_{0, t}$ and $\hat{\omega}_{j, t}$ do not show up in the linearised equations (3.1) and (3.2) of the model. ${ }^{11}$

${ }^{8}$ The details of how the coefficients $\gamma_{b}$ and $\gamma_{f}$ relate to the underlying structure are slightly different for each formulation. For example, we have $\gamma_{b}+\gamma_{f}<1$ under the hybrid NKPC and $\gamma_{b}+\gamma_{f}=1$ under the indexation formulation.

${ }^{9}$ On the other hand, Sbordone (2002) and Lubik and Schorfheide (2004) present results for the United States which support the purely forward-looking NKPC.

${ }^{10}$ Jondeau and LeBihan (2003) find that omitted dynamics may explain the discrepancies between ML and GMM estimates of the hybrid model. Eichenbaum and Fisher (2003) interpret the significance of lagged inflation as arising due to measurement errors in the data.

${ }^{11}$ In the state-dependent simulations we have to make sure that the out-of-steady-state adjustment probabilities are not greater than one or less than zero. This constraint is critical for adjustment probabilities which are close to one in the steady state, ie for firms with a relatively old price. Therefore, we keep the adjustment probabilities constant at their steady-state values for an accumulated $2 \%$ of the oldest price vintages. For the remaining 98\%, the adjustment probabilities fluctuate around their steadystate values. If a probability takes a value greater than one or smaller than zero the shock is drawn again. With the calibration we are using this case arises only rarely. 
We then estimate (5.1) under the restriction $\hat{\gamma}_{f}+\hat{\gamma}_{b}=1$ using the GMM approach. ${ }^{12}$ The instrument set comprises of four lags each of inflation, real marginal costs and the output gap. ${ }^{13}$ Table 2 summarises the estimation results based on the artificial data sets generated under $3 \%$ steady-state inflation. We present the mean estimates of the coefficients $\lambda, \gamma_{f}$ and $\gamma_{b}$ over the respective 1,000 data sets. The interval in square brackets is given by the $10 \%$ and the $90 \%$ quantiles of the distributions of coefficient estimates. If this interval includes zero, the share of the 1,000 data sets with a significant t-value is given in brackets. $J^{*}$ indicates the fraction of the 1,000 data sets where the Sargan-Hansen instrument validity test is passed.

The estimation results do not vary much across the three adjustment cost distribution functions. The estimated forward-looking inflation coefficient, $\hat{\gamma_{f}}$, dominates the backward-looking inflation coefficient, $\hat{\gamma_{b}}$. The point estimates of the marginal cost coefficient, $\hat{\lambda}$, are positive but small. When the data sets are generated by SD simulations (implying time-varying adjustment behaviour), $\hat{\lambda}$ is significant only in a small fraction of the simulated data sets independent of the type of adjustment cost distribution. Interestingly, the point estimates displayed in Table 2 based on simulated data are close to those reported in Galí et al. (2003). Their estimates are $\hat{\gamma_{b}}=0.355, \hat{\gamma_{f}}=0.627$, and $\hat{\lambda}=0.014$ (all statistically significant) based on post-war US data from the

1960 Q1-1997 Q4 period over which the average annual inflation is approximately 4\%.

Next, we compare the distribution of correlations between fundamental inflation and effective inflation. ${ }^{14}$ Effective inflation is the inflation generated by the full state-dependent model. Fundamental inflation, in turn, refers to the inflation dynamics implied by the estimated hybrid NKPC. To compute fundamental inflation, inflation in (5.1) is rewritten as a function of lagged

\footnotetext{
${ }^{12}$ Dotsey (2002) conducts a similar experiment. He estimates (5.1) based on data generated by a three-period forward-looking truncated Calvo model under zero steady-state inflation. The estimated coefficient on lagged inflation, $\hat{\gamma}_{b}$, is positive, statistically significant, and of the same magnitude as the one estimated by Galí and Gertler (1999). Hence, Dotsey (2002) points out that there may be pitfalls in interpreting the estimated lagged coefficient as one arising from backward-looking rule-of-thumb pricing behaviour. He also discusses the issue of instrument validity in the case where additional lags of inflation appear in the specification.

${ }^{13}$ This lag length corresponds to that typically used in the empirical literature. See, for example, Galí and Gertler (1999).

${ }^{14}$ Kurmann (2002) reports the distribution of the correlation between observed and fundamental inflation based on the purely forward-looking NKPC.
} 
Table 2: Estimation results for the hybrid NKPC, $\pi_{S S}=3 \%$

\begin{tabular}{|c|c|c|c|c|c|}
\hline \multirow[b]{2}{*}{ ADJUSTMENT COSTS } & \multicolumn{5}{|c|}{ DATA GENERATING PROCESS: TD } \\
\hline & $\hat{\lambda}$ & $\hat{\gamma}_{f}$ & $\hat{\gamma}_{b}$ & $J^{*}$ & $\mathrm{D}$ \\
\hline \multirow[t]{2}{*}{ Flat C.D.F. } & $0.012(0.32)$ & 0.573 & 0.427 & 0.98 & 6 \\
\hline & {$[-0.002,0.027]$} & {$[0.455,0.702]$} & & & \\
\hline \multirow[t]{2}{*}{ S-shaped C.D.F. } & $0.012(0.36)$ & 0.555 & 0.445 & 0.98 & 6 \\
\hline & {$[-0.000,0.026]$} & {$[0.462,0.667]$} & & & \\
\hline \multirow[t]{4}{*}{ Linear C.D.F. } & $0.012(0.39)$ & 0.539 & 0.461 & 0.98 & 6 \\
\hline & {$[-0.001,0.025]$} & {$[0.459,0.63]$} & & & \\
\hline & \multicolumn{5}{|c|}{ DATA GENERATING PROCESS: SD } \\
\hline & $\hat{\lambda}$ & $\hat{\gamma}_{f}$ & $\hat{\gamma}_{b}$ & $J^{*}$ & $\mathrm{D}$ \\
\hline \multirow[t]{2}{*}{ Flat C.D.F. } & $0.002(0.04)$ & 0.541 & 0.459 & 0.95 & 6 \\
\hline & {$[-0.006,0.01]$} & {$[0.453,0.639]$} & & & \\
\hline \multirow[t]{2}{*}{ S-shaped C.D.F. } & $0.009(0.07)$ & 0.567 & 0.433 & 0.95 & 6 \\
\hline & {$[-0.028,0.048]$} & {$[0.469,0.684]$} & & & \\
\hline \multirow[t]{2}{*}{ Linear C.D.F. } & $0.007(0.08)$ & 0.621 & 0.379 & 0.93 & 6 \\
\hline & {$[-0.034,0.05]$} & {$[0.495,0.773]$} & & & \\
\hline
\end{tabular}

Notes: $\gamma_{f}+\gamma_{b}=1$.

$J^{*}=$ proportion of 1,000 simulations passing the $J$-test.

$D=$ average duration of price stickiness. 
Table 3: Estimation results for the hybrid NKPC, $\pi_{S S}=6 \%$

\begin{tabular}{|c|c|c|c|c|c|}
\hline \multirow[b]{2}{*}{ ADJUSTMENT COSTS } & \multicolumn{5}{|c|}{ DATA GENERATING PROCEss: TD } \\
\hline & $\hat{\lambda}$ & $\hat{\gamma}_{f}$ & $\hat{\gamma}_{b}$ & $J^{*}$ & $\mathrm{D}$ \\
\hline \multirow[t]{2}{*}{ Flat C.D.F. } & $0.019(0.34)$ & 0.568 & 0.432 & 0.98 & 4.6 \\
\hline & {$[-0.003,0.044]$} & {$[0.466,0.699]$} & & & \\
\hline \multirow[t]{2}{*}{ S-shaped C.D.F. } & $0.029(0.59)$ & 0.568 & 0.432 & 0.97 & 4.5 \\
\hline & {$[0.006,0.054]$} & {$[0.486,0.677]$} & & & \\
\hline \multirow[t]{4}{*}{ Linear C.D.F. } & $0.036(0.69)$ & 0.551 & 0.449 & 0.98 & 4.2 \\
\hline & {$[0.008,0.065]$} & {$[0.479,0.643]$} & & & \\
\hline & \multicolumn{5}{|c|}{ DATA GENERATING PROCESS: SD } \\
\hline & $\hat{\lambda}$ & $\hat{\gamma}_{f}$ & $\hat{\gamma}_{b}$ & $J^{*}$ & $\mathrm{D}$ \\
\hline \multirow[t]{2}{*}{ Flat C.D.F. } & $0.014(0.07)$ & 0.649 & 0.351 & 0.94 & 4.6 \\
\hline & {$[-0.015,0.05]$} & {$[0.515,0.823]$} & & & \\
\hline \multirow[t]{2}{*}{ S-shaped C.D.F. } & $0.010(0.03)$ & 0.711 & 0.289 & 0.95 & 4.5 \\
\hline & {$[-0.039,0.058]$} & {$[0.549,0.920]$} & & & \\
\hline \multirow[t]{2}{*}{ Linear C.D.F. } & $0.098(0.35)$ & 0.592 & 0.408 & 0.73 & 4.2 \\
\hline & {$[-0.062,0.283]$} & {$[0.443,0.766]$} & & & \\
\hline
\end{tabular}

Notes: $\gamma_{f}+\gamma_{b}=1$.

$J^{*}=$ proportion of 1,000 simulations passing the $J$-test.

$D=$ average duration of price stickiness. 
Figure 6: Distribution of correlations between effective and fundamental inflation, $\pi_{s s}=$ $3 \%$

Data from SD simulations

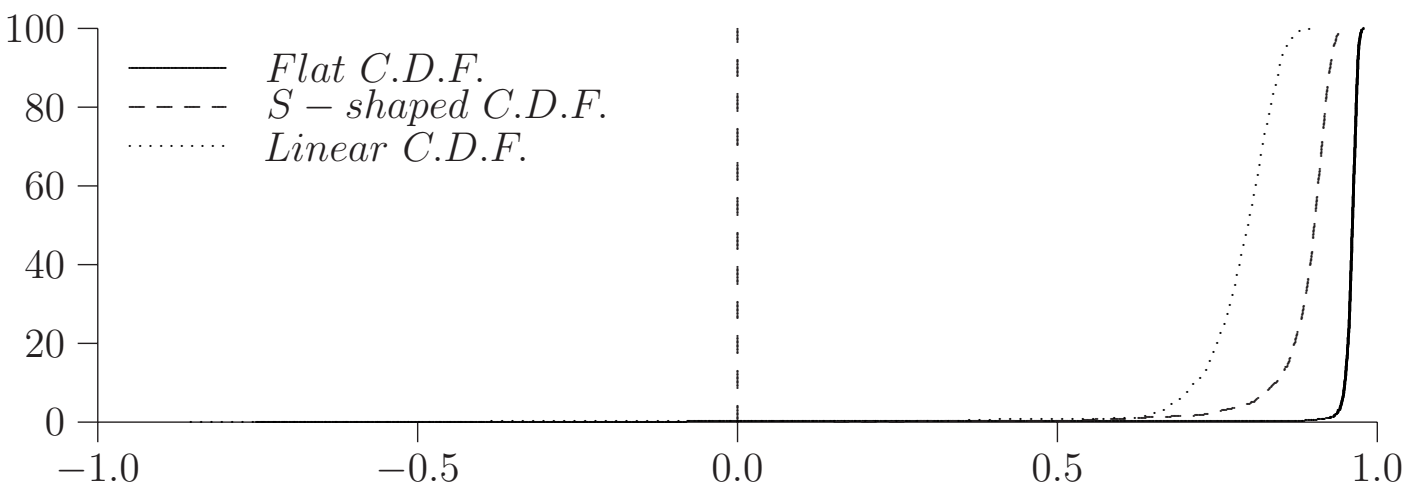

Data from TD simulations

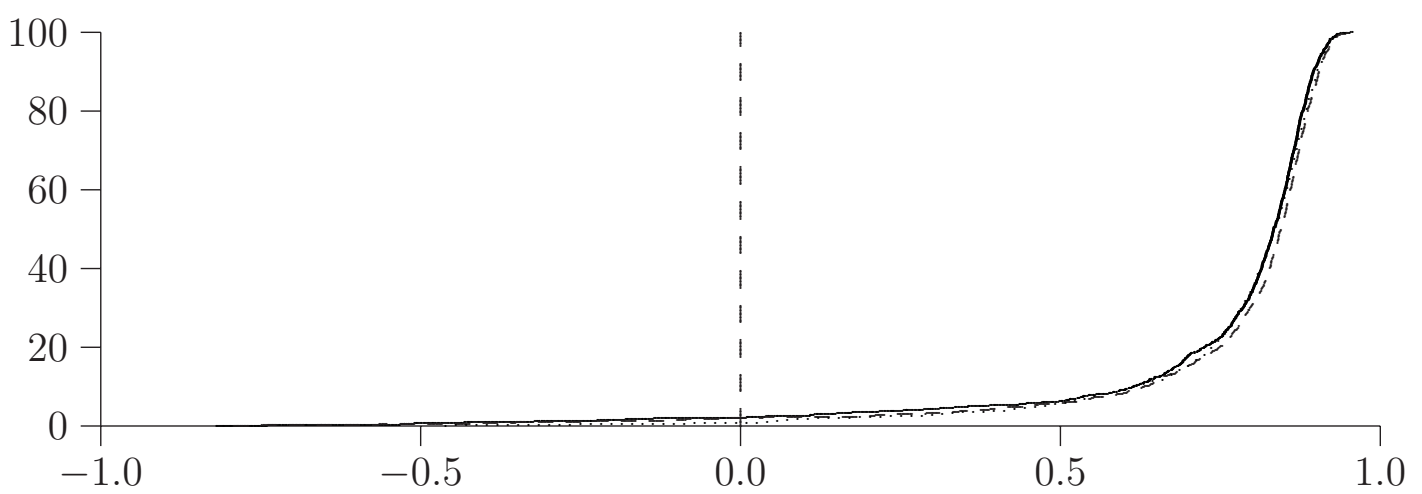

inflation and of the expected path of future real marginal costs, as in Galí and Gertler (1999):

$$
\pi_{t}=\delta_{1} \pi_{t-1}+\frac{\hat{\lambda}}{\delta_{2} \hat{\gamma}_{f}} \sum_{j=0}^{\infty}\left(\frac{1}{\delta_{2}}\right)^{j} E_{t} m c_{t+j}
$$

where $\delta_{1}$ and $\delta_{2}$ denote the eigenvalues of the estimated equation (5.1). The data for expected future marginal costs are generated using a bivariate $\operatorname{VAR}(2)$ with inflation and marginal cost.

The results summarised in Figure 6 refer to TD and SD simulated data sets. They show high correlations between fundamental and effective inflation in all six cases considered. The highest correlation results from the SD simulated data sets generated by the model with the flat C.D.F.: in over $90 \%$ of the 1,000 simulations, the correlation is greater than 0.9 . This is of the magnitude found in the empirical literature. Gagnon and Khan (2004), for example, report estimates implying that the correlation between observed inflation and fundamental inflation 
Figure 7: Distribution of correlations between effective and fundamental inflation, $\pi_{s s}=$ $6 \%$

Data from SD simulations

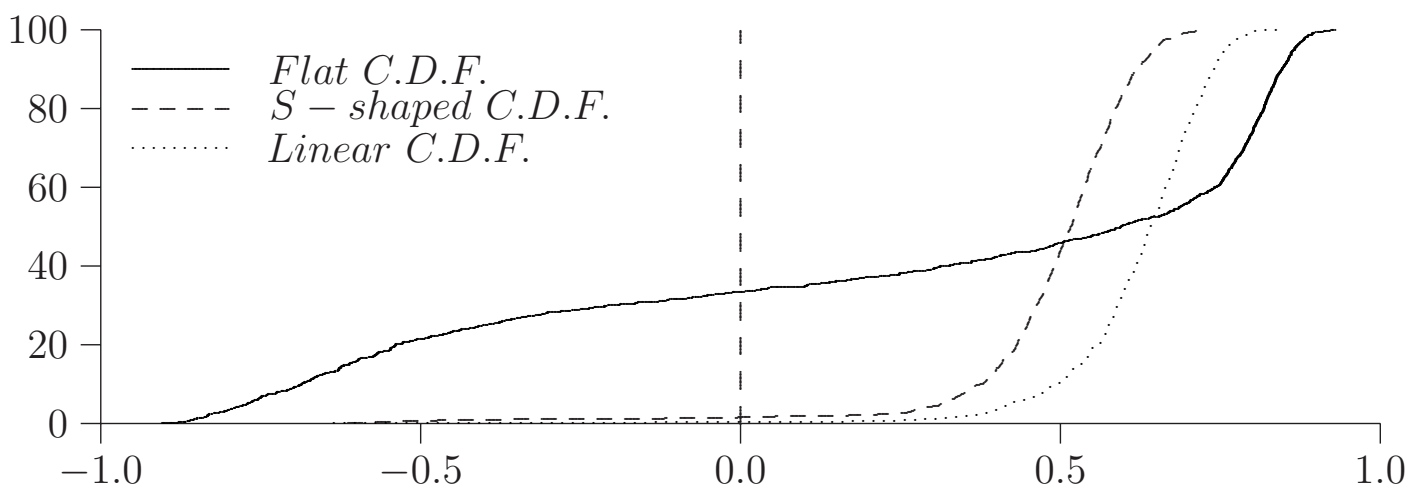

Data from TD simulations

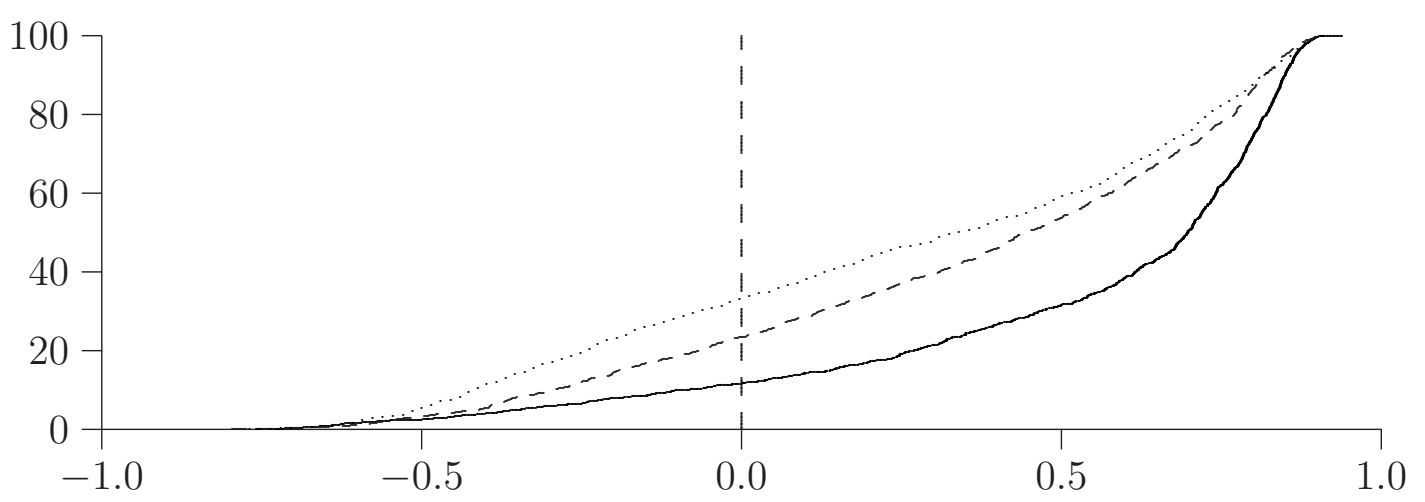

based on the hybrid NKPC is 0.88 for the United States, 0.91 for Canada, and 0.92 for the euro area.

Taken together, the results in Table 2 and the correlations in Figure 6 suggest that for $3 \%$ steady-state inflation the hybrid NKPC is a good approximation to the inflation dynamics implied by the underlying models of price-setting. In other words, the misspecification of the hybrid model is small. This result is not robust to an increase in trend inflation, however. In Table 3 and Figure 7, we report results for the same type of exercise under the assumption of $6 \%$ steady-state inflation. Although point estimates remain qualitatively similar, the correlations between fundamental and effective inflation deteriorate markedly. This indicates that the misspecification of the hybrid model has increased significantly. 
To explore the factors which contribute to this result, we make use of the information

provided by Charts 1, 4 and 5. In Figure 4, the coefficients on expected future inflation, $\delta_{j}^{\prime}$, and on current and expected future marginal cost, $\psi_{j}^{\prime}$, have a pattern resembling the geometric pattern of the corresponding coefficients in the SDPC representation of the Calvo model displayed in Figure 1. In the Calvo model, the geometric pattern collapses to just two terms denoting the expectation of next period's inflation and current real marginal costs. Consequently, one lead of inflation and the current marginal cost term will turn out to be a good approximation of the higher order lead structure in the SDPC, if the lead structure of the $\delta_{j}^{\prime}$ s and $\psi_{j}^{\prime}$ s approximates that geometric pattern well. In this case, the forward-looking structure of the SDPC indicates a relatively small deviation from its counterpart in the hybrid NKPC.

At higher levels of steady-state inflation, the lead structure of the SDPC differs evidently from the monotonically declining geometric lead pattern implied by the NKPC. As shown by Figure 5 (for $6 \%$ steady-state inflation and the S-shape C.D.F.), the number of price vintages declines and the size of the coefficients is modified. Thus, one lead of inflation becomes a poor approximation for the lead structure of the SDPC. At the same time, the weight on the most recent lags on inflation becomes larger. The estimates of the hybrid NKPC still turn out to be similar as under the $3 \%$ case; but the correlation between effective (model-based) and fundamental (hybrid NKPC-based) inflation deteriorates indicating stronger misspecification for the hybrid NKPC.

\section{Conclusions}

In this paper we have used the state-dependent pricing model of Dotsey et al. (1999) to derive a general specification for the Phillips curve which allows for positive steady-state inflation and state-dependent price-setting behaviour. In the state-dependent Phillips curve (SDPC) inflation depends on current and expected future real marginal costs, past and expected future inflation, and past and expected future fluctuations in the price adjustment pattern. The specific nature of firms' price-setting behaviour and the deep structural parameters of the model, such as the level of steady-state inflation or the elasticity of substitution, have important implications for the structure of the SDPC. 
Also, we have demonstrated that the dynamics of inflation generated by simulations of various variants of the Dotsey et al. (1999) model are highly correlated with those implied by the estimated hybrid NKPC. This suggests that the hybrid NKPC with its parsimonious structure provides a good reduced-form description of inflation dynamics for a broad class of time and state-dependent price-setting behaviours. By comparing the structure of the SDPC with the SDPC representation of the Calvo (1983) model underlying the NKPC, we find that this result holds as long as the distribution of the different vintages falls smoothly and in a slightly convex pattern. For our adjustment cost distribution functions, this property holds if steadystate inflation is low (3\%), but not if inflation rates are as high as $6 \%$. We draw two conclusions: first, the hybrid NKPC can be a good description of inflation dynamics in an economy that allows for state-dependent pricing, particularly at low trend inflation rates. Second, the coefficients of the hybrid NKPC may not have a structural interpretation. In this sense, the hybrid NKPC may still share the weaknesses of the traditional Phillips curve approach. 


\section{A Log-linearization of the main pricing equations}

Log-linearisation of the optimal nominal price set by adjusting firms:

Consider the first-order condition for an optimal nominal price, as given by equation (2.8) in the text. After some rearrangement, we obtain

$$
\begin{aligned}
E_{t} \sum_{j=0}^{J-1} \beta^{j} Q_{t, t+j} \frac{\omega_{j, t+j}}{\omega_{0, t}}\left[\frac{P_{0, t}}{P_{t}} \frac{P_{t}}{P_{t+j}}\right]^{1-\theta} C_{t+j}= \\
\qquad \frac{\theta}{\theta-1} E_{t} \sum_{j=0}^{J-1} \beta^{j} Q_{t, t+j} \frac{\omega_{j, t+j}}{\omega_{0, t}} M C_{t+j}\left[\frac{P_{0, t}}{P_{t}} \frac{P_{t}}{P_{t+j}}\right]^{-\theta} C_{t+j}
\end{aligned}
$$

Replacing $P_{0, t} / P_{t}$ by $X_{0, t}$ and using $P_{t} / P_{t+j}=1 / \prod_{i=1}^{j} \Pi_{t+i}$, (A.1) can be rewritten as

$$
\begin{aligned}
E_{t} \sum_{j=0}^{J-1} \beta^{j} Q_{t, t+j} \frac{\omega_{j, t+j}}{\omega_{0, t}}\left[\frac{1}{\prod_{i=1}^{j} \Pi_{t+i}}\right]^{1-\theta} C_{t+j} X_{0, t}= \\
\qquad \frac{\theta}{\theta-1} E_{t} \sum_{j=0}^{J-1} \beta^{j} Q_{t, t+j} \frac{\omega_{j, t+j}}{\omega_{0, t}} M C_{t+j}\left[\frac{1}{\prod_{i=1}^{j} \pi_{t+i}}\right]^{-\theta} C_{t+j}
\end{aligned}
$$

Log-linearising (A.2) around the steady-state values $\omega_{j}=\omega_{j}, \forall j=0, \ldots, J-1, C=C$, $\Pi=\Pi, X=\frac{P_{0}}{P}, Q=1$, and $M C=M C$ yields

$$
\begin{aligned}
& E_{t} \sum_{j=0}^{J-1}\left[q_{t, t+j}+\hat{\omega}_{j, t+j}-\hat{\omega}_{0, t}+(\theta-1) \sum_{i=1}^{j} \pi_{t+i}+c_{t+j}+x_{0, t}\right] \beta^{j} \frac{\omega_{j}}{\omega_{0}} \Pi^{j(\theta-1)} C X= \\
& \frac{\theta}{\theta-1} E_{t} \sum_{j=0}^{J-1}\left[q_{t, t+j}+\hat{\omega}_{j, t+j}-\hat{\omega}_{0, t}+m c_{t+j}+\theta \sum_{i=1}^{j} \pi_{t+i}+c_{t+j}\right] \beta^{j} \frac{\omega_{j}}{\omega_{0}} \Pi^{j \theta} C M C
\end{aligned}
$$

where $\hat{\omega}$-terms denote absolute deviations and the other time-varying lower-case letters denote percentage deviations of variables from their respective steady-states values. Using

$$
X=\frac{\theta}{\theta-1} \frac{\sum_{j=0}^{J-1} \beta^{j} \omega_{j} \Pi^{j \theta}}{\sum_{j=0}^{J-1} \beta^{j} \omega_{j} \Pi^{j(\theta-1)}} M C
$$


we can solve for the optimal relative price:

$$
\begin{aligned}
x_{0, t}=E_{t} \sum_{j=0}^{J-1}\left[q_{t, t+j}+\hat{\omega}_{j, t+j}-\hat{\omega}_{0, t}+m c_{t+j}+\theta \sum_{i=1}^{j} \pi_{t+i}+c_{t+j}\right] \frac{\beta^{j} \omega_{j} \Pi^{j \theta}}{\sum_{i=0}^{J-1} \beta^{i} \omega_{i} \Pi^{i \theta}} \\
\quad-E_{t} \sum_{j=0}^{J-1}\left[q_{t, t+j}+\hat{\omega}_{j, t+j}-\hat{\omega}_{0, t}+(\theta-1) \sum_{i=1}^{j} \pi_{t+i}+c_{t+j}\right] \frac{\beta^{j} \omega_{j} \Pi^{j(\theta-1)}}{\sum_{i=0}^{J-1} \beta^{i} \omega_{i} \Pi^{i(\theta-1)}}
\end{aligned}
$$

Relating real marginal cost fluctuations to the fluctuations of output, we can write

$$
c_{t}=\kappa m c_{t}
$$

where $\kappa$ denotes the elasticity of aggregate demand with respect to real marginal costs. If the expected future fluctuations of the stochastic discount factors, $q_{t+j}$, are ignored, substituting (A.6) into (A.5) and rearranging yields

$$
x_{0, t}=E_{t} \sum_{j=1}^{J-1} \sum_{i=j}^{J-1}\left[\theta \rho_{i}+(1-\theta) \delta_{i}\right] \pi_{t+j}+E_{t} \sum_{j=0}^{J-1}\left\{\psi_{j} m c_{t+j}+\left(\rho_{j}-\delta_{j}\right)\left[\hat{\omega}_{j, t+j}-\hat{\omega}_{0, t}\right]\right\}
$$

where

$$
\rho_{j}=\frac{\beta^{j} \omega_{j} \Pi^{j \theta}}{\sum_{i=0}^{J-1} \beta^{i} \omega_{i} \Pi^{i \theta}} \quad \delta_{j}=\frac{\beta^{j} \omega_{j} \Pi^{j(\theta-1)}}{\sum_{i=0}^{J-1} \beta^{i} \omega_{i} \Pi^{i(\theta-1)}} \quad \psi_{j}=\rho_{j}+\kappa\left(\rho_{j}-\delta_{j}\right)
$$

Equation (A.7) corresponds to (3.1) in the text.

Log-linearisation of the aggregate price level:

Consider the aggregate price level described by (2.10) in the text:

$$
P_{t}=\left[\sum_{j=0}^{J-1} \omega_{j, t}\left(P_{0, t-j}\right)^{1-\theta}\right]^{\frac{1}{1-\theta}}
$$

Equation (A.8) can be rewritten such that all elements are constant along the inflationary steady state:

$$
1=\sum_{j=0}^{J-1}\left[\omega_{j, t}\left(\frac{P_{0, t-j}}{P_{t}}\right)^{1-\theta}\right]=\sum_{j=0}^{J-1}\left[\omega_{j, t}\left(\frac{P_{0, t-j}}{P_{t-j}} \frac{P_{t-j}}{P_{t}}\right)^{1-\theta}\right]
$$

Replacing $P_{0, t-j} / P_{t-j}$ by $X_{0, t-j}$ and $P_{t-j} / P_{t}$ by $1 / \prod_{i=0}^{j-1} \Pi_{t-i}$, we obtain

$$
1=\sum_{j=0}^{J-1} \omega_{j, t} \frac{X_{0, t-j}^{1-\theta}}{\prod_{i=0}^{j-1} \Pi_{t-i}{ }^{1-\theta}}
$$


Log-linearising (A.10) around the steady-state values $X_{0, t-j}=X, \omega_{j}=\omega_{j}$, and $\Pi=\Pi$ gives

$$
0=\sum_{j=0}^{J-1}\left[\frac{X^{1-\theta}}{\Pi^{j(1-\theta)}} \hat{\omega}_{j, t}+(1-\theta) \omega_{j} \frac{X^{1-\theta}}{\Pi^{j(1-\theta)}} x_{0, t-j}-(1-\theta) \omega_{j} \frac{X^{1-\theta}}{\Pi^{j(1-\theta)}} \sum_{i=0}^{j-1} \pi_{t-i}\right]
$$

where again $\hat{\omega}$-terms denote absolute deviations and the other time-varying lower-case letters denote percentage deviations of variables from their respective steady-states values. Since $X=$ $P_{0} / P$, we have

$$
0=\left(\frac{P_{0}}{P}\right)^{1-\theta} \sum_{j=0}^{J-1}\left[\Pi^{j(\theta-1)}\left(\frac{1}{1-\theta} \hat{\omega}_{j, t}+\omega_{j}\left(x_{0, t-j}-\sum_{i=0}^{j-1} \pi_{t-i}\right)\right)\right]
$$

Solving for the optimal relative price, $x_{0, t}$, yields, after some rearrangement,

$$
x_{0, t}=\frac{1}{\omega_{0}}\left[\sum_{j=0}^{J-2} \sum_{i=j+1}^{J-1} \omega_{i} \Pi^{i(\theta-1)} \pi_{t-j}-\sum_{j=1}^{J-1} \omega_{j} \Pi^{j(\theta-1)} x_{0, t-j}+\frac{1}{1-\theta} \sum_{j=0}^{J-1} \Pi^{j(\theta-1)} \hat{\omega}_{j, t}\right]
$$

Equation (A.13) corresponds to (3.2) in the text.

\section{B Derivation of the SDPC coefficients}

Consider (3.1) and (3.3). Combining these two equations and solving for $\pi_{t}$, one obtains

$$
\begin{array}{r}
\pi_{t}=\frac{1}{\mu_{0}}\left[E_{t} \sum_{j=1}^{J-1} \sum_{i=j}^{J-1}\left[\theta \rho_{i}+(1-\theta) \delta_{i}\right] \pi_{t+j}+E_{t} \sum_{j=0}^{J-1} \psi_{j} m c_{t+j}+E_{t} \sum_{j=0}^{J-1}\left(\rho_{j}-\delta_{j}\right)\left[\hat{\omega}_{j, t+j}-\hat{\omega}_{0, t}\right]\right. \\
\left.-\sum_{j=1}^{J-2} \mu_{j} \pi_{t-j}+\sum_{j=1}^{J-1} \omega_{j} \nu_{j} x_{0, t-j}-\frac{1}{1-\theta} \hat{\Omega}_{t}\right]
\end{array}
$$

where

$$
\begin{array}{ccc}
\rho_{j}=\frac{\beta^{j} \omega_{j} \Pi^{j \theta}}{\sum_{i=0}^{J-1} \beta^{i} \omega_{i} \Pi^{i \theta}} \quad \delta_{j}=\frac{\beta^{j} \omega_{j} \Pi^{j(\theta-1)}}{\sum_{i=0}^{J-1} \beta^{i} \omega_{i} \Pi^{i(\theta-1)}} & \psi_{j}=\rho_{j}+\kappa\left(\rho_{j}-\delta_{j}\right) \\
\mu_{j}=\frac{1}{\omega_{0}} \sum_{i=j+1}^{J-1} \omega_{i} \Pi^{i(\theta-1)} \quad \nu_{j}=\frac{1}{\omega_{0}} \Pi^{j(\theta-1)} & \hat{\Omega}_{t}=\sum_{j=0}^{J-1} \nu_{j} \hat{\omega}_{j, t}
\end{array}
$$

Using (3.2) and applying matrix notation, the weighted lagged relative price terms in (B.1), can be written as

$$
H \vec{x}_{t}=H A \vec{\pi}_{t}-H B x_{t-1}+H C \vec{\Omega}_{t}
$$


where

$$
\begin{aligned}
& \vec{x}_{t}=\left[\begin{array}{c}
x_{0, t-1} \\
x_{0, t-2} \\
\vdots \\
x_{0, t-(J-1)} \\
\vdots \\
x_{0, t-2 J+2} \\
\vdots \\
x_{0, t-T}
\end{array}\right] \quad \vec{\pi}_{t}=\left[\begin{array}{c}
\pi_{t-1} \\
\pi_{t-2} \\
\vdots \\
\pi_{t-(J-1)} \\
\vdots \\
\pi_{t-2 J+2} \\
\vdots \\
\pi_{t-T}
\end{array}\right] \quad \vec{\Omega}_{t}=\left[\begin{array}{c}
\hat{\Omega}_{t-1} \\
\hat{\Omega}_{t-2} \\
\vdots \\
\hat{\Omega}_{t-(J-1)} \\
\vdots \\
\hat{\Omega}_{t-2 J+2} \\
\vdots \\
\hat{\Omega}_{t-T}
\end{array}\right] \\
& H=\left[\begin{array}{rrrrrrrr}
\omega_{1} \nu_{1} & 0 & \cdots & \cdots & \cdots & \cdots & \cdots & 0 \\
0 & \omega_{2} \nu_{2} & 0 & \cdots & \cdots & \cdots & \cdots & \vdots \\
\vdots & \ddots & \ddots & \ddots & \ddots & \ddots & \ddots & \vdots \\
\vdots & \ddots & \ddots & \omega_{J-1} \nu_{J-1} & 0 & \cdots & \cdots & \vdots \\
\vdots & \ddots & \ddots & \ddots & 0 & \ddots & \ddots & \vdots \\
\vdots & \ddots & \ddots & \ddots & \ddots & \ddots & \ddots & \vdots \\
\vdots & \ddots & \ddots & \ddots & \ddots & \ddots & \ddots & \vdots \\
0 & \cdots & \cdots & \cdots & \cdots & \cdots & \cdots & 0
\end{array}\right] \\
& A=\left[\begin{array}{rrrrrrrr}
\mu_{0} & \mu_{1} & \cdots & \mu_{J-2} & 0 & \cdots & \cdots & 0 \\
0 & \mu_{0} & \mu_{1} & \ldots & \mu_{J-2} & 0 & \cdots & \vdots \\
\vdots & \ddots & \ddots & \ddots & \ddots & \ddots & \ddots & \vdots \\
\vdots & \ddots & \ddots & \ddots & \ddots & \ddots & \ddots & 0 \\
\vdots & \ddots & \ddots & 0 & \mu_{0} & \mu_{1} & \cdots & \mu_{J-2} \\
\vdots & \ddots & \ddots & \ddots & \ddots & 0 & \cdots & 0 \\
\vdots & \ddots & \ddots & \ddots & \ddots & \ddots & \ddots & \vdots \\
0 & \cdots & \cdots & \cdots & \cdots & \cdots & \cdots & 0
\end{array}\right] \\
& B=\left[\begin{array}{rrrrrrrr}
\omega_{1} \nu_{1} & \omega_{2} \nu_{2} & \cdots & \omega_{J-1} \nu_{J-1} & 0 & \cdots & \cdots & 0 \\
0 & \omega_{1} \nu_{1} & \omega_{2} \nu_{2} & \cdots & \omega_{J-1} \nu_{J-1} & 0 & \cdots & \vdots \\
\vdots & \ddots & \ddots & \ddots & \ddots & \ddots & \ddots & \vdots \\
\vdots & \ddots & \ddots & \ddots & \ddots & \ddots & \ddots & 0 \\
\vdots & \ddots & \ddots & 0 & \omega_{1} \nu_{1} & \omega_{2} \nu_{2} & \cdots & \omega_{J-1} \nu_{J-1} \\
\vdots & \ddots & \ddots & \ddots & \ddots & 0 & \cdots & 0 \\
\vdots & \ddots & \ddots & \ddots & \ddots & \ddots & \ddots & \vdots \\
0 & \cdots & \cdots & \cdots & \cdots & \cdots & \cdots & 0
\end{array}\right]
\end{aligned}
$$




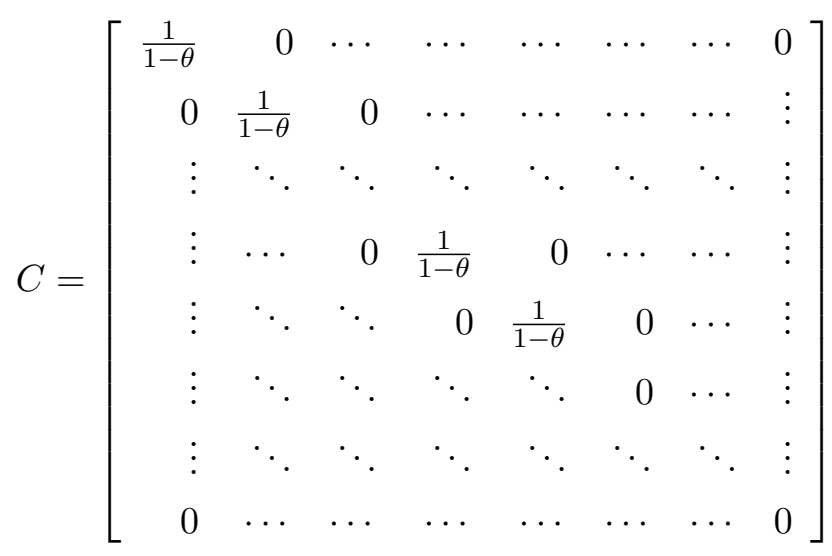

By iterative backward substitution, the lagged relative price terms in (B.2) can be expressed in terms of lagged inflation rates and lagged deviations of the distributions of price vintages from their steady-state distribution:

$$
\begin{gathered}
H \vec{x}_{t}=H A \vec{\pi}_{t}-H B x_{t-1}+H C \vec{\Omega}_{t} \\
=H A \vec{\pi}_{t}-H B\left[A \pi_{t-1}-B x_{t-2}+C \Omega_{t-1}\right]+H C \vec{\Omega}_{t} \\
\vdots \\
=\sum_{j=0}^{k} H(-B)^{j}\left[A \vec{\pi}_{t-j}+C \vec{\Omega}_{t-j}\right]+H(-B)^{k+1} x_{t-(k+1)} \\
\vdots \\
=\lim _{k \rightarrow \infty} \sum_{j=0}^{k} H(-B)^{j}\left[A \vec{\pi}_{t-j}+C \vec{\Omega}_{t-j}\right]
\end{gathered}
$$

Thus, if we unwind the lagged relative price terms in (B.2) to the infinite past, (B.1) can be expressed as

$$
\pi_{t}=E_{t} \sum_{j=1}^{J-1} \delta_{j}^{\prime} \pi_{t+j}+E_{t} \sum_{j=0}^{J-1} \psi_{j}^{\prime} m c_{t+j}+E_{t} \sum_{j=0}^{J-1} \gamma_{j}\left[\hat{\omega}_{j, t+j}-\hat{\omega}_{0, t}\right]+\sum_{j=1}^{\infty} \mu_{j}^{\prime} \pi_{t-j}+\sum_{j=0}^{\infty} \varrho_{j} \hat{\Omega}_{t-j}
$$

where

$$
\begin{gathered}
\delta_{j}^{\prime}=\frac{1}{\mu_{0}} \sum_{i=j}^{J-1}\left[\theta \rho_{i}+(1-\theta) \delta_{i}\right]=\frac{\omega_{0}}{\sum_{k=1}^{J-1} \omega_{k} \Pi^{k(\theta-1)}} \sum_{i=j}^{J-1}\left[\theta \frac{\beta^{i} \omega_{i} \Pi^{i \theta}}{\sum_{k=0}^{J-1} \beta^{k} \omega_{k} \Pi^{k \theta}}+(1-\theta) \frac{\beta^{i} \omega_{i} \Pi^{i(\theta-1)}}{\sum_{k=0}^{J-1} \beta^{k} \omega_{k} \Pi^{k(\theta-1)}}\right] \\
\psi_{j}^{\prime}=\frac{1}{\mu_{0}} \psi_{j}=\frac{\omega_{0}}{\sum_{i=1}^{J-1} \omega_{i} \Pi^{i(\theta-1)}} \frac{\beta^{j} \omega_{j} \Pi^{j \theta}}{\sum_{i=0}^{J-1} \beta^{i} \omega_{i} \Pi^{i \theta}}+\kappa\left(\frac{\beta^{j} \omega_{j} \Pi^{j \theta}}{\sum_{i=0}^{J-1} \beta^{i} \omega_{i} \Pi^{i \theta}}-\frac{\beta^{j} \omega_{j} \Pi^{j(\theta-1)}}{\sum_{i=0}^{J-1} \beta^{i} \omega_{i} \Pi^{i(\theta-1)}}\right)
\end{gathered}
$$




$$
\begin{gathered}
\gamma_{j}=\frac{1}{\mu_{0}}\left(\rho_{j}-\delta_{j}\right)=\frac{\omega_{0}}{\sum_{i=1}^{J-1} \omega_{i} \Pi^{i(\theta-1)}}\left(\frac{\beta^{j} \omega_{j} \Pi^{j \theta}}{\sum_{i=0}^{J-1} \beta^{i} \omega_{i} \Pi^{i \theta}}-\frac{\beta^{j} \omega_{j} \Pi^{j(\theta-1)}}{\sum_{i=0}^{J-1} \beta^{i} \omega_{i} \Pi^{i(\theta-1)}}\right) \\
\mu_{j}^{\prime}=\frac{1}{\mu_{0}}\left(\sum_{i=1}^{j} \vec{e}\left[H(-B)^{i-1} A\right]_{[., j-(i-1)]}-\mu_{j}\right), \quad \mu_{j}=0, \forall j \geq J-1 \\
\varrho_{0}=-\frac{1}{\mu_{0}} \frac{1}{1-\theta} \quad \varrho_{j}=\frac{1}{\mu_{0}} \sum_{i=1}^{j} \vec{e}\left[H(-B)^{i-1} C\right]_{[., j-(i-1)]} \quad \forall j \geq 1
\end{gathered}
$$

Note that $\vec{e}$ is a unity row vector with $[(j+1)(J-1)-1]$ elements and that the matrices $H$, $A, B$ and $C$ are square matrices of order $[(j+1)(J-1)-1]$. The subscript $[., j-(i-1)]$ then denotes the column of matrix $\left[H(-B)^{(i-1)} A\right]$ and $\left[H(-B)^{(i-1)}\right]$ which are premultiplied by $\vec{e}$. 


\section{References}

Ascari, G.: 2004, Staggered price and trend inflation: some nuisances, Review of Economic Dynamics 7, 642-67.

Bakhshi, H., Burriel-Llombart, P., Khan, H. and Rudolf, B.: 2003, Endogenous price stickiness, trend inflation, and the New Keynesian Phillips curve, Working Paper 191, Bank of England.

Burstein, A.: 2002, Inflation and output dynamics with state-dependent pricing decisions, manuscript, Northwestern University.

Calvo, G.: 1983, Staggered prices in a utility-maximizing framework, Journal of Monetary Economics 12, 383-98.

Caplin, A. and Leahy, J.: 1991, State-dependent pricing and the dynamics of money and output, Quarterly Journal of Economics 106, 683-708.

Christiano, L., Eichenbaum, M. and Evans, C.: 2001, Nominal rigidity and the dynamic effects of a shock to monetary policy, manuscript, Northwestern University.

Dotsey, M.: 2002, Pitfalls in interpreting tests of backward-looking pricing in New Keynesian models, Federal Reserve Bank of Richmond Economic Quarterly 88, 37-50.

Dotsey, M., King, R. and Wolman, A.: 1999, State-dependent pricing and the general equilibrium dynamics of money and output, Quarterly Journal of Economics 114, 655-90.

Eichenbaum, M. and Fisher, J.: 2003, Testing the Calvo model of sticky prices, manuscript, Northwestern University.

Gagnon, E. and Khan, H.: 2004, New Phillips curve under alternative technologies for Canada, the United States, and the Euro area, European Economic Review.

Galí, J. and Gertler, M.: 1999, Inflation dynamics: a structural econometric analysis, Journal of Monetary Economics 44, 195-222.

Galí, J., Gertler, M. and López-Salido, J.: 2001, European inflation dynamics, European Economic Review 45, 1,237-70. 
Galí, J., Gertler, M. and López-Salido, J.: 2003, Robustness of the estimates of the hybrid New Keynesian Phillips curve, manuscript, University of Pombeu Fabra.

Golosov, M. and Lucas, R.: 2003, Menu costs and Phillips curves, manuscript, Federal Reserve Bank of Minneapolis.

Guerrieri, L.: 2002, Inflation persistence of staggered contracts, manuscript, Board of Governors of the Federal Reserve System.

Jondeau, E. and LeBihan, H.: 2003, ML vs GMM estimates of hybrid macroeconomic models (with an application to the 'New Phillips Curve'), manuscript, Banque de France.

Klenow, P. and Kryvtsov, O.: 2003, State-dependent or time-dependent pricing: does it matter of recent U.S. inflation?, Manuscript, Federal Reserve Bank of Minneapolis.

Kozicki, S. and Tinsley, P.: 2002, Alternative sources of the lag dynamics of inflation, manuscript, Federal Reserve Bank of Kansas City.

Kurmann, A.: 2002, Maximum likelihood estimation of dynamic stochastic theories with an application to New Keynesian pricing, manuscript, UQAM.

Leith, C. and Malley, J.: 2002, Estimated general equilibrium models for the evaluation of monetary policy in the US and Europe, manuscript, University of Glasgow.

Linde, J.: 2003, Estimating New Keynesian Phillips curves: a full information maximum liklihood approach, manuscript .

Lubik, T. and Schorfheide, F.: 2004, Testing for indeterminacy: An application to U. S. monetary policy, American Economic Review 94, 190-217.

Mash, R.: 2003, New Keynesian microfoundations revisited: a general Calvo-Taylor model and the desirability of inflation vs. price level targeting, Oxford University Discussion Paper 109.

Rudd, J. and Whelan, K.: 2002, New tests of the new Keynesian Phillips curve, Federal reserve board discussion paper no. 2001-30.

Sbordone, A.: 2002, Prices and unit labor costs: a new test of price stickiness, Journal of Monetary Economics 49, 265-92. 
Sbordone, A.: 2003, A limited information approach to the simultaneous estimation of wage and price dynamics, manuscript, Rutgers University.

Sheshinski, E. and Weiss, Y.: 1983, Optimum pricing policy under stochastic inflation, Review of Economic Studies 50, 513-29.

Smets, F. and Wouters, R.: 2003, An estimated stochastic dynamic general equilibrium model of the euro area, Journal of the European Economic Association 1, 1,123-75.

Taylor, J.: 1980, Aggregate dynamics and staggered contracts, Journal of Political Economy $88,1-24$.

Wolman, A.: 1999, Sticky prices, marginal cost, and the behavior of inflation, Federal Reserve Bank of Richmond Economic Quarterly 85, 29-48.

Wolman, A.: 2000, The frequency and costs of individual price ajdustment, Federal Reserve Bank of Richmond Economic Quarterly 86, 1-22.

Woodford, M.: 2003, Interest and prices: foundations of a theory of monetary policy, Princeton University Press, Princeton, New Jersey. 
Swiss National Bank Working Papers published since 2004:

2004-1 Samuel Reynard: Financial Market Participation and the Apparent Instability of Money Demand

2004-2 Urs W. Birchler and Diana Hancock: What Does the Yield on Subordinated Bank Debt Measure?

2005-1 Hasan Bakhshi, Hashmat Khan and Barbara Rudolf: The Phillips curve under state-dependent pricing 
Swiss National Bank Working Papers are also available at www.snb.ch, section Publications/Research Subscriptions or individual issues can be ordered at Swiss National Bank, Fraumünsterstrasse 8, CH-8022 Zurich, fax +41 4463181 14, E-mail library@snb.ch 